\title{
Crosstalk between nitric oxide and hypoxia- inducible factor signaling pathways: an update
}

\author{
This article was published in the following Dove Press journal: \\ Research and Reports in Biochemistry \\ 18 June 2015 \\ Number of times this article has been viewed
}

\author{
Marina D Hendrickson \\ Robert O Poyton \\ Department of Molecular, Cellular, \\ and Developmental Biology, \\ University of Colorado, Boulder, \\ CO, USA
}

\begin{abstract}
Hypoxia-inducible factor-1 (HIF-1) is responsible for cellular adaptations to hypoxia. While oxygen $\left(\mathrm{O}_{2}\right)$ negatively regulates its stability, many other factors affect HIF-1 stability and activity, including nitric oxide (NO). $\mathrm{NO}$ derived from L-arginine and nitrite $\left(\mathrm{NO}_{2}^{-}\right)$could nitrosylate or nitrate HIF-1 and multiple proteins involved in HIF-1 regulation, and can allow HIF-1 to escape normoxic degradation. In turn, HIF-1 can increase NO production through multiple mechanisms, including increased inducible nitric oxide synthase (iNOS) expression and subunit 4-2 of cytochrome c oxidase (COX4-2) expression. There is therefore a high degree of crosstalk between HIF-1 and NO signaling. As such, many cellular responses to NO are mediated by HIF-1, and vice versa. This includes, but is not limited to, angiogenesis, apoptosis, senescence, and metabolic changes. These pathways all have important functions in normal physiology and when altered can contribute or, in some cases, lead to pathogenesis.
\end{abstract}

Keywords: HIF, nitric oxide, Cco/NO mitochondrial signaling, ROS/RNS, cancer

\section{Introduction}

HIF-1, a member of a family of hypoxia-inducible transcription factors (HIFs), was discovered in 1992, during studies on the oxygen-dependent regulation of erythropoietin expression. ${ }^{1}$ It is a heterodimer containing a novel $\alpha$ subunit (HIF-1 $\alpha$ ) and a previously characterized $\beta$ subunit (HIF-1 $\beta$ or aryl hydrocarbon receptor nuclear translocator [ARNT]). Given that cellular HIF-1 levels and activity increased rapidly upon hypoxia, HIF-1 was assumed to be a key mediator of the cellular hypoxic response. ${ }^{2}$ Twenty years later, knowledge about HIF-1 and other HIFs has increased dramatically in both quantity and complexity. One important focus of research has been on the relationship between nitric oxide (NO), a reactive nitrogen species (RNS) and important signaling molecule, and HIF-1. HIF-NO signaling has been implicated in many physiological and pathophysiological processes, which has served to further increase interest in their complex connection. This review will cover much of what has been learned since the identification of HIF-1, and address gaps in our understanding of HIF-1 and how it is influenced by and influences NO production.

\section{HIF background}

The HIF family consists of three $\alpha$ isoforms, HIF- $1 \alpha$, HIF- $2 \alpha$, and HIF- $3 \alpha$, and three $\beta$ isoforms, ARNT, ARNT2, and ARNT3, most of which are subject to alternative splicing. ${ }^{3-6}$ All members of the HIF family are basic helix-loop-helix (bHLH) proteins containing two Per-ARNT-Sim (PAS) domains, PAS A and PAS B (Figure 1). The HIF- $\alpha$ isoforms contain an oxygen-dependent degradation domain (ODDD)
Department of Molecular, Cellular, and Developmental Biology,

University of Colorado, 347 UCB, Boulder, CO 80309-0347, USA

Tel +I 3034923823

Fax + I 3034928789

Email robert.poyton@colorado.edu 


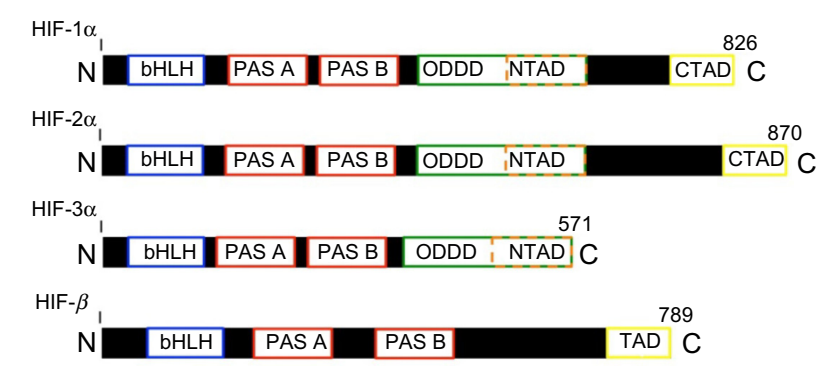

Figure I A comparison of the HIF family members shows varying degrees of conservation.

Notes: This comparison shows that all HIF family members contain a bHLH domain, which allows the dimerized proteins to bind to DNA, and two PAS domains, PAS A and PAS B, which facilitate dimerization. HIF-I $\alpha$ and HIF- $2 \alpha$ also contain CTADs and the HIF- $\beta$ s have a TAD, both of which allow p300 to bind the dimerized factor and increase transcriptional activity. ${ }^{8}$

Abbreviations: HIF-I, hypoxia-inducible factor I; PAS, Per-ARNT-Sim; CTAD, C-terminal activation domain; TAD, transactivation domain; ODDD, oxygen-dependent degradation domain.

and an N-terminal activation domain (NTAD), and HIF-1 $\alpha$ and HIF- $2 \alpha$ also contain a C-terminal activation domain (CTAD). ${ }^{7}$ The $\alpha$ isomers are class I bHLH-PAS factors and are capable of dimerizing with any of the $\beta$ isomers, which are class II bHLH-PAS factors. ${ }^{8}$ However, as the tissue distribution of each isomer is variable, some combinations may not be physiologically relevant. While HIF- $1 \alpha$ and HIF-1 $\beta /$ ARNT are expressed ubiquitously, HIF-2 $\alpha$, HIF-3 $\alpha$, ARNT2, and ARNT3 appear to have more limited patterns of expression in normoxia. ${ }^{1,3,5,6}$ During hypoxia, HIF- $2 \alpha$ expression is induced in all tissues, but only within select cell types, and this pattern also holds true for HIF-3 $\alpha$, albeit within different subsets of cells. ${ }^{9-11}$

The different HIF isomers have a high degree of homology and all bind to hypoxic-response elements (HREs) to induce transcription. However, each isomer has unique gene targets and can produce different and sometimes oppositional effects within the cell. ${ }^{12}$ HIF-1 is primarily responsible for the acute hypoxic response, influencing the expression of genes involved in a variety of cellular pathways, including angiogenesis, metabolism, cell survival, and apoptosis. ${ }^{10,13}$ HIF-2 (HIF-2 $\alpha$ and ARNT) is also stabilized by hypoxia, and is the primary factor responsible for increased erythropoietin (EPO) and red blood cell production during prolonged hypoxia, but also increases expression of stem cell factors and antioxidant enzymes, such as superoxide dismutase 1 and $2 \cdot{ }^{10,14,15}$ The role of HIF-3 (HIF-3 $\alpha$ and ARNT) within the cell is unclear. However, one HIF- $3 \alpha$ splice variant functions as a negative regulator of HIF- 1 by binding and sequestering ARNT. ${ }^{16}$ Although HIF-2 and HIF-3 have important roles in physiology and pathophysiology, HIF-1 has the most diverse and nuanced role in the cell and is the HIF most influenced by NO signaling.
In normoxia, the ODDD of HIF- $\alpha$ is hydroxylated via prolyl hydroxylase domain (PHD) family proteins, ubiquitinated by von Hippel-Lindau protein (VHL), and subsequently degraded via the 26S proteosome. ${ }^{17,18}$ The PHD family has three members, and each play a unique role in regulating HIF- $\alpha$ levels, with PHD2 as the primary isoform controlling HIF-1 $\alpha$ levels in normoxia. PHD2 is a 2 -oxoglutarate (2-OG, or $\alpha$-ketoglutarate) $\mathrm{O}_{2}$-dependent enzyme with an oxidizable $\mathrm{Fe}^{2+}$ center, and is capable of hydroxylating both Pro564 and Pro402 of HIF-1 $\alpha$. After catalysis, ascorbate reduces the oxidized iron center back into the active state. ${ }^{19}$ Hydroxylation of HIF- $1 \alpha$ allows the E3 ubiquitin ligase VHL to ubiquitinate HIF-1 $\alpha$ at Lys532, Lys538, or Lys547. Ubiquitination of any of these sites targets HIF- $1 \alpha$ to the $26 \mathrm{~S}$ proteasome for degradation. ${ }^{20}$

HIF- $1 \alpha$ is modified in other ways besides proline hydroxylation, including acetylation, phosphorylation, asparagine hydroxylation, and S-nitrosylation. Most of these modifications are in the ODDD or activation domains of HIF-1 $\alpha$ (Figure 2). In addition to proline hydroxylation by PHD, factor-inhibiting HIF-1 $\alpha$ (FIH) hydroxylates Asn803 (851 in HIF-2 $\alpha$ ) in the CTAD during normoxia, which prevents HIF from binding transcriptional coactivator $\mathrm{p} 300 .{ }^{21}$ Knockout studies indicate the CTAD of HIF is primarily responsible for metabolic gene induction. ${ }^{22}$ Mice lacking FIH have increased intracellular ATP, oxygen consumption, and tidal volumes, and have decreased body masses and EPO production during hypoxia, largely as a result of HIF-1 activity. Interestingly, this effect is also seen in neuron-specific knockouts, indicating that HIF-1 activity in one part of the body can induce widespread metabolic changes. ${ }^{22}$ As FIH is also a 2-OG and $\mathrm{Fe}^{2+}$

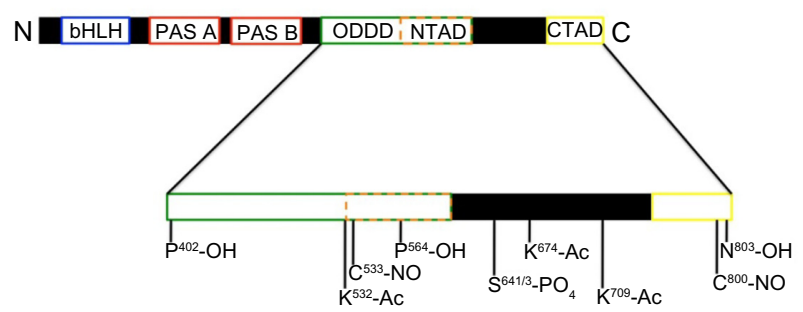

Figure 2 Post-translational modifications of HIF-I $\alpha$.

Notes: HIF-I $\alpha$ is capable of being modified in many ways, and most modifications fall in the C-terminal half of the protein. HIF-I $\alpha$ is hydroxylated at Pro402 and Pro564 by PHD family members and at Asn 803 by FIH. ${ }^{19,21} \mathrm{HIF}-\mathrm{I} \alpha$ can be acetylated at Lys 532 by Arrest-defective-I protein (ARDI), Lys674 by p300/CBP associated factor (PCAF), and Lys709 by $\mathrm{p} 300 .{ }^{82,85,165} \mathrm{HIF}-\mathrm{I} \alpha$ is also phosphorylated at Ser64I/3 by $\mathrm{P} 42 / 44$ mitogen-activated protein kinase (MAPK). ${ }^{87}$ S-nitrosylation of HIF-I $\alpha$ has been observed at Cys533 and Cys800. ${ }^{70-72}$ This figure does not include all known modifications of HIF-I $\alpha$, but those most relevant to this review.

Abbreviations: HIF-I $\alpha$, hypoxia-inducible factor I $\alpha$; PHD, prolyl hydroxylase domain; ARDI, arrest-defective-I protein; CBP, CREB-binding protein; PCAF, p300/CBP associated factor; MAPK, mitogen activated protein kinase; PAS, Per-ARNT-Sim. 
dependent dioxygenase, regulation of HIF-1 by FIH is also $\mathrm{O}_{2}$-dependent. Because FIH has a lower $\mathrm{O}_{2} K_{\mathrm{m}}$ than PHD2, there is a graded response to hypoxia based on HIF-1 NTAD and CTAD activity. ${ }^{23}$

Hypoxia results in altered expression of over 1,000 mammalian genes due, in large part, to increased HIF-1 activity. ${ }^{24}$ ChIP-sequencing (chromatin immunoprecipitation) identified over 500 HIF-1 binding sites throughout the human genome, though not all are associated with altered gene expression. ${ }^{25}$ The genes under HIF-1 control are involved in a variety of cellular processes, with the cumulative goal of minimizing cellular damage from hypoxia and returning oxygen supply to cells and tissues (Table 1). To increase perfusion, HIF-1 induces vascular endothelial growth factor (VEGF) and VEGF receptor 1 (VEGFR1) production, which stimulates angiogenesis. ${ }^{26} \mathrm{HIF}-1$ also stimulates expression of inducible nitric oxide synthase (iNOS) to increase NO production, which leads to vasodilation and increased blood and oxygen delivery to cells by activating guanylyl cyclase and relaxing smooth muscle cells. ${ }^{27}$

HIF-1 also engages multiple pathways to minimize damage from hypoxia. While it was initially thought that limited $\mathrm{O}_{2}$ during hypoxia resulted in lower oxidative phosphorylation and ATP levels, this lowered respiration is actually attributable to HIF-1. HIF-1 induces expression of several metabolic enzymes, including glycolytic enzymes and pyruvate dehydrogenase kinase 1 (PDK1). PDK1

Table I A representative list of proteins whose expression is regulated by HIF-I

\begin{tabular}{|c|c|}
\hline Pathway & Proteins involved \\
\hline Angiogenesis & VEGF-A, ${ }^{161}$ PDGFA, ${ }^{162}$ VEGFR-I ${ }^{163}$ \\
\hline Cell survival & Met, ${ }^{160}$ IGF-2, ${ }^{163}$ IGFBP-| ${ }^{163}$ \\
\hline Apoptosis & BNIP3, ${ }^{163}$ NOXA ${ }^{162}$ \\
\hline \multirow[t]{2}{*}{ Metabolism } & PDK, ${ }^{83}$ PGKI, ${ }^{161}$ GAPDH, ${ }^{161} \mathrm{HK} 2,{ }^{161}$ \\
\hline & GLUTI, ${ }^{164} \mathrm{HO}-\left.\right|^{164}$ \\
\hline Secreted factors & TGF $\alpha,{ }^{161}$ TGF $\beta,{ }^{161}$ EPO ${ }^{161}$ \\
\hline HIF regulation & PHD3 $^{161}$ \\
\hline NO production & iNOS, ${ }^{161} \mathrm{COX} 4-2^{88}$ \\
\hline Autophagy & $\mathrm{BNIP3}^{30}$ \\
\hline
\end{tabular}

Notes: Many of these processes are influenced by factors outside of HIF-I regulation. For example, although apoptotic and prosurvival proteins are induced by HIF-I, the environment in which they are expressed will ultimately determine whether HIF-I promotes apoptosis or survival.

Abbreviations: HIF-I, hypoxia-inducible factor I; VEGF-A, vascular endothelial growth factor A; VEGFR-I, VEGF receptor-I; IGF-2, insulin-like growth factor 2 PDGFA, platelet-derived growth factor subunit A; IGFBP-I, insulin-like growth factor binding protein-I; iNOS, inducible nitric oxide synthase; BNIP3, BCL2/adenovirus EIB 19 kDa protein-interacting protein 3; NOXA, phorbol-I2-myristate-I3-acetateinduced protein I; PHD3, prolyl hydroxylase domain 3; PDK, pyruvate dehydrogenase kinase; PGKI, phosphglycerate kinase I; GAPDH, glyceraldehyde-3-phosphate dehydrogenase; HK2, hexokinase 2; GLUTI, glucose transporter I; HO-I, heme oxygenase I; TGF $\alpha$, transforming growth factor $\alpha$; TGF $\beta$, transforming growth factor $\beta$; EPO, erythropoietin. phosphorylates and inactivates pyruvate dehydrogenase, thus preventing pyruvate from entering the TCA cycle and switching cellular energy production from respiration to glycolysis. ${ }^{28}$ HIF-1 also inhibits $\beta$-oxidation of fatty acids and promotes mitophagy, both of which further limit respiratory activity. ${ }^{29,30}$

The HIF-1 heterodimer is capable of interacting with many proteins. The bHLH of HIF- $\alpha$ and HIF- $\beta$ allow HIF to bind to DNA, but interaction with p300 or CREB-binding protein (CBP) is necessary for full induction HIF-1 and HIF-2 target genes. Although p300/CBP interacts with the CTAD/TAD of HIF, it increases expression of both CTAD and NTAD target genes. ${ }^{22}$ HIF-1 also interacts with the tyrosine kinase Src in a multitude of ways, including direct binding of Src to complexed HIF-1 $\alpha$-HIF-1 $\beta$-p300. ${ }^{31}$ Regardless of the manner in which it interacts with HIF, Src is necessary for VEGF production and the full response to hypoxia. ${ }^{32,33}$ Signal transducer and activator of transcription 3 (STAT3) is another way by which Src can influence HIF-1 activity. Src phosphorylates STAT3, which allows STAT3 to form a complex with HIF-1, p300, and redox effector factor-1 (Ref-1) to induce VEGF expression. ${ }^{34}$ As seen above, these proteins can alter HIF-1's activity in both general and specific ways, adding another regulatory dimension to HIF-1.

\section{Two distinct cellular pathways for nitric oxide synthesis}

Nitric oxide and reactive nitrogen species derived from it are important signaling molecules that function in several different biological pathways and pathologies including: systemic blood pressure, the upregulation of hypoxic genes (hypoxic signaling), the regulation of stress response pathways, host-microbe interactions, immune signaling, and apoptosis. ${ }^{35-42}$ It is important to emphasize that cells have two distinct pathways for NO synthesis, and that these pathways can function differentially in HIF signaling.

\section{L-arginine-dependent NO synthesis by nitric oxide synthases (NOS)}

Until recently, the three isozymes of nitric oxide synthase (NOS) - endothelial (eNOS), inducible (iNOS), and neuronal (nNOS) - were thought to be the major intracellular sources of cellular NO. Both eNOS and nNOS are expressed constitutively and are activated by calcium $\left(\mathrm{Ca}^{2+}\right)$, while the expression of iNOS is inducible. These enzymes catalyze L-arginine-dependent NO synthesis in the presence of $\mathrm{NAD}(\mathrm{P}) \mathrm{H}$ and oxygen (Equation 1). Although the L-arginine NOS pathway is oxygen-dependent, the precise oxygen 
concentration threshold below which this pathway fails to function is unclear. However, it is clear that the L-arginine pathway for NO synthesis becomes less effective as the oxygen levels drop and is likely to be nonexistent under hypoxic conditions (see "Mitochondrial signaling - free radicals and HIF signaling" section) (Figure 3). ${ }^{43}$

$$
\begin{gathered}
2 \mathrm{~L}-\text { Arginine }+3 \mathrm{NADPH}+3 \mathrm{H}^{+}+4 \mathrm{O}_{2} \rightarrow 2 \mathrm{NO}+2 \\
\mathrm{~L}-\text { Citrulline }+3 \mathrm{NADP}^{+}+4 \mathrm{H} 2 \mathrm{O}
\end{gathered}
$$

\section{Nitrite-dependent NO synthesis by mitochondrial cytochrome $c$ oxidase}

It is now clear that cells have a second pathway for NO synthesis. This pathway involves the reduction of nitrite $\left(\mathrm{NO}_{2}^{-}\right)$to $\mathrm{NO}$ and is catalyzed by a handful of heme-containing proteins (Equation 2). ${ }^{44,45}$ These include: hemoglobin, myoglobin, xanthine oxidase, $\mathrm{P} 450$. cytochrome c oxidase, and, under some conditions, cytochrome c. ${ }^{45}$ Interest in this NOS-independent route for biological NO synthesis is growing because $\mathrm{O}_{2}^{-}$is now considered to be a circulating reservoir for NO in mammals and because of the potential therapeutic applications of this alternative route for NO synthesis. ${ }^{46,47}$ As mentioned, one of the enzymes that functions to convert $\mathrm{O}_{2}^{-}$to $\mathrm{NO}$ is mitochondrial cytochrome c oxidase $(\mathrm{Cco})$, in a reaction that has been designated $\mathrm{Cco} / \mathrm{NO} \cdot{ }^{37,48}$ As the terminal member of the mitochondrial electron transport chain, Cco uses electrons derived ultimately from a reduced metabolite to convert $\mathrm{O}_{2}^{-}$to $\mathrm{NO}$ at physiological $\mathrm{pH}$ and $\mathrm{O}_{2}^{-}$concentrations. ${ }^{39,49}$ $\mathrm{NO}$ produced by $\mathrm{Cco} / \mathrm{NO}$ has been reported to participate in hypoxic gene induction in both yeast and mammalian cells and may be involved in the metabolic reprogramming that accompanies the increased longevity brought about by dietary restriction. ${ }^{36-39,50}$ In addition, given that some of the $\mathrm{NO}$ produced by $\mathrm{Cco} / \mathrm{NO}$ is released from human endothelial

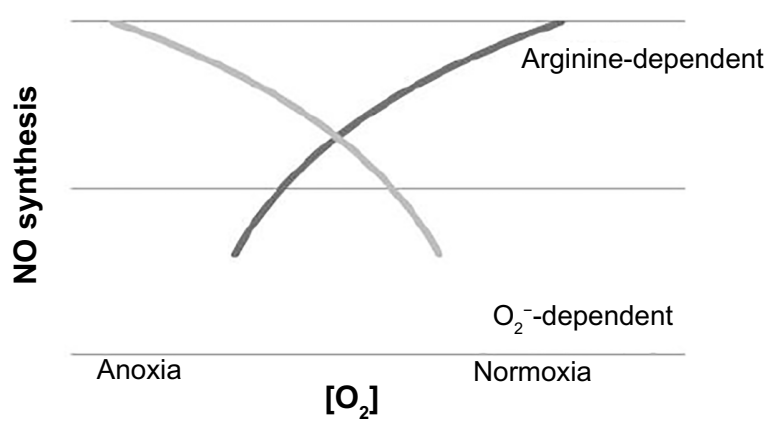

Figure $3 \mathrm{~A}$ model for the effects of oxygen on arginine and $\mathrm{O}_{2}^{-}$-dependent $\mathrm{NO}$ synthesis.

Notes: Nitrite-dependent $\mathrm{NO}$ synthesis is favored at low $\mathrm{O}_{2}$ levels while the arginine-dependent pathway for $\mathrm{NO}$ synthesis is favored at high $\mathrm{O}_{2}$ levels. Abbreviation: NO, nitric oxide. cells and that heme proteins in blood vessel walls catalyze $\mathrm{O}_{2}^{-}$-dependent $\mathrm{NO}$ synthesis and vasorelaxation of aortic rings, it is possible that $\mathrm{Cco} / \mathrm{NO}$ produced-NO also functions in vasodilation..$^{51,52}$

$$
\mathrm{Fe}^{2+}+\mathrm{O}_{2}^{-}+\mathrm{H}^{+} \rightarrow \mathrm{Fe}^{3+}+\mathrm{NO}+\mathrm{OH}^{-}
$$

\section{Differential regulation of the two pathways for NO synthesis}

These two pathways for NO synthesis are differentially regulated by oxygen. While the arginine-dependent pathway is optimal at high oxygen levels and is oxidative, the $\mathrm{O}_{2}^{-}$dependent pathway is favored by low oxygen levels and is reductive (Figure 3 ). This indicates that tissue oxygen concentrations can regulate which pathway is active and under what conditions.

However, other factors can regulate these two pathways for NO synthesis as well (Table 2). For example, the argininedependent pathway can be regulated by the arginine analogs $\mathrm{N}^{\mathrm{G}}$, $\mathrm{N}^{\mathrm{G}}$-dimethyl-L-arginine (ADMA) and $\mathrm{N}^{\mathrm{G}}$-methyl-L-arginine (L-NMA), as well as calcium. ${ }^{53}$ And the Cco/NO pathway is regulated by both subunit isoform switching and by the ratio of ADP to ATP (Castello et al., unpublished). ${ }^{54} \mathrm{Cco}$ is a genetic chimera composed of three polypeptide subunits encoded on mitochondrial DNA and 6-9 subunits encoded on nuclear DNA. ${ }^{55}$ While the mitochondrially-encoded subunit polypeptides make up a core that contains the catalytic center of the enzyme, the nuclear-encoded subunit polypeptides function in the assembly of the holoenzyme or in regulating

\begin{tabular}{|c|c|c|c|}
\hline \multicolumn{4}{|c|}{ Regulators of activity } \\
\hline \multicolumn{2}{|l|}{ NOS } & \multicolumn{2}{|c|}{$\mathrm{O}_{2}^{-}$-dependent } \\
\hline Positive & Negative & Positive & Negative \\
\hline$\overline{\mathrm{O}_{2}}$ & NO & $\mathrm{O}_{2}^{-}$ & $\mathrm{O}_{2}$ \\
\hline L-Arginine & ADMA & $\mathrm{H}^{+}$ & ATPa \\
\hline $\mathrm{Ca}^{2+\mathrm{a}}$ & L-NMA & ADPa & $\operatorname{cox} 5 a^{a}$ \\
\hline $\mathrm{H}^{+}$ & & $\operatorname{coX} 5 b^{a}$ & \\
\hline NADPH & & & \\
\hline
\end{tabular}
its catalytic activity. ${ }^{55}$ Both yeast and mammalian Cco have

Table 2 Positive and negative regulators of NO production

Notes: Arginine and $\mathrm{O}_{2}^{-}$-dependent $\mathrm{NO}$ production each have various activators and inhibitors. In addition to positive and negative feedback by substrates and products, NOS is inhibited by the arginine analogs ADMA and L-NMA, and nNOS and eNOS are induced by increases in $\mathrm{Ca}^{2+}$. $\mathrm{O}_{2}^{-}$-dependent reactions are also subject to feedback regulation. Cco/NO activity is dependent on which subunit 5 isoform is present $-5 a$ or $5 b$ (yeast) - and ATP/ADP levels. High ADP increases Cco/NO activity, while high ATP inhibits it. ${ }^{a}$ Denotes $\mathrm{Cco} / \mathrm{NO}$ specific regulators of activity.

Abbreviations: $\mathrm{NO}$, nitric oxide; $\mathrm{Ca}^{2+}$, calcium; $\mathrm{NADPH}$, nicotinamide adenine dinucleotide phosphate; ADMA, $N^{G}, N^{G}$-dimethyl-L-arginine; L-NMA, $N^{G}$-methyl-Larginine; NOS, nitric oxide synthase; $\mathrm{O}_{2}^{-}$, nitrite; $\mathrm{COX} 5$ a, yeast cytochrome coxidase subunit 5 isoform a; COX5b, yeast cytochrome c oxidase subunit 5 isoform b; $\mathrm{O}_{2}$, oxygen; ATP, adenosine triphosphate; ADP, adenosine diphosphate. 
oxygen-regulated isoforms for one of the nuclear encoded subunits, $\mathrm{Va}$ and $\mathrm{Vb}$ in yeast and COX4-1 and COX4-2 in mammals. Yeast Cco isozymes engineered to carry different oxygen-regulated subunit $\mathrm{V}$ isoforms exhibit markedly different oxygen sensitivities, with the subunit $\mathrm{Vb}$ isoform supporting NO synthesis at oxygen concentrations as high as $160 \mu \mathrm{M}$ and the subunit Va isoform supporting NO synthesis only at oxygen concentrations below $15 \mu \mathrm{M} .{ }^{54}$ Recently, we have found that ADP and ATP act differentially to modulate $\mathrm{Cco} / \mathrm{NO}$ activity and that high $\mathrm{ADP} / \mathrm{ATP}$ ratios reduce the sensitivity of $\mathrm{Cco} / \mathrm{NO}$ to $\mathrm{O}_{2}$, allowing for $\mathrm{NO}$ synthesis at oxygen concentrations that are well into the normoxic range for most tissues (see "Mitochondrial signaling - free radicals and HIF signaling" section) (Castello et al., unpublished). This indicates that, in addition to functioning under hypoxia, $\mathrm{Cco} / \mathrm{NO}$ can also serve as a source of NO in normoxic cells and tissues.

\section{Mitochondrial signaling - free radicals and HIF signaling}

It has long been known that mitochondria, and the free radicals they produce, function in cell signaling pathways and a variety of cellular processes, including nuclear gene expression, hypoxic signaling, cancer and normal cell proliferation, inflammation, autophagy, stem cell differentiation, and aging. ${ }^{37,57-59}$ The type of mitochondrial free radical produced is largely dependent on oxygen concentration (Figure 4). Under normoxic conditions (20-130 $\mu \mathrm{M} \mathrm{O}_{2}$ ), superoxide $\left(\mathrm{O}_{2}^{-}\right)$and hydrogen peroxide $\left(\mathrm{H}_{2} \mathrm{O}_{2}\right)$ are prevalent, under hypoxic conditions $\left(20-2 \mu \mathrm{M} \mathrm{O}_{2}\right)$, peroxynitrite $\left(\mathrm{ONOO}^{-}\right.$; formed through the reaction of $\mathrm{NO}$ with $\left.\mathrm{O}_{2}^{-}\right)$is prevalent, and under anoxic conditions (less than $2 \mu \mathrm{M} \mathrm{O}_{2}$ ), NO is prevalent. As shown in Figure 4, each of these free radicals can modify proteins that affect HIF-1 $\alpha$ stability and activity.

Several studies have implicated the mitochondrial respiratory chain in the induction of hypoxic genes (hypoxic signaling) when cells experience hypoxia and have proposed that increased mitochondrial free radical production by hypoxic mitochondria is involved. As yet, the mitochondrial free radical(s) involved in hypoxic signaling has (have) not been conclusively identified. Early evidence suggested the involvement of superoxide produced by complex III. ${ }^{37}$ However, this is unlikely because the rate of superoxide production decreases with oxygen concentration and recent studies have reported that neither complex III nor free radicals generated by complex III in hypoxic cells are required for HIF-1 $\alpha$ stability. ${ }^{60,61}$ So, although it is well documented that cells
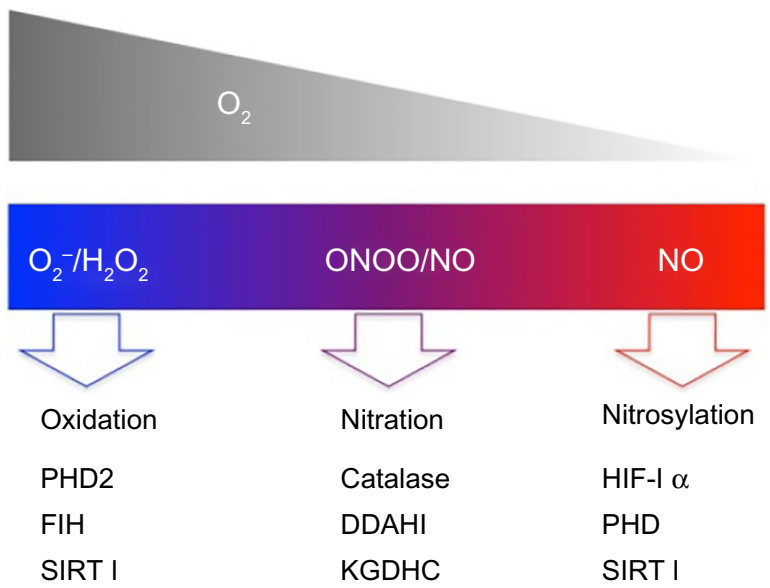

Figure 4 Impact of $\mathrm{O}_{2}$ levels on ROS/RNS signaling.

Notes: $\mathrm{O}_{2}$ levels have a large impact on ROS/RNS signaling. High $\mathrm{O}_{2}^{-}$and $\mathrm{H}_{2} \mathrm{O}_{2}$ can stabilize HIF- $\mathrm{I} \alpha$ by oxidizing and inhibiting PHD2 and FIH though FIH appears to be far more sensitive to these oxidants. ${ }^{23,166,167}$ SIRTI activity is also negatively affected by $\mathrm{ROS}^{84} \mathrm{~A}$ mix of high ROS production and high NO production results in the formation of highly toxic molecules such as $\mathrm{ONOO}^{-}$. $\mathrm{ONOO}^{-}$is capable of nitrating a large number of proteins, including dimethylarginine dimethylaminohydrolase I (DDAHI), catalase, and $\alpha$-ketoglutarate (or 2-OG) dehydrogenase complex $(\mathrm{KGDHC})$, which results in decreased activity of all three enzymes. DDAHI is fundamental to NOS functioning by facilitating removal of inhibitors ADMA and L-NMA, and catalase removes $\mathrm{H}_{2} \mathrm{O}_{2}$ from cells. ${ }^{168} \mathrm{KGDHC}$ is a tricarboxylic acid cycle enzyme, and its inhibition will decrease 2-OG levels and affect PHD/FIH function. ${ }^{169}$ High NO production coupled with low ROS allows for thiol nitrosylation, which can affect HIF-I $\alpha$, PHD2, and SIRTI. ${ }^{70,73,84}$

Abbreviations: RNS, reactive nitrogen species; $\mathrm{O}_{2}^{-}$, superoxide; $\mathrm{H}_{2} \mathrm{O}_{2}$, hydrogen peroxide; ONOO-, peroxynitrite; HIF-I $\alpha$, hypoxia-inducible factor I $\alpha$; NO, nitric oxide; PHD2, prolyl hydroxylase domain 2; FIH, factor inhibiting HIF-I; SIRTI, sirtuin I; DDAHI, dimethylarginine dimethylaminohydrolase I; KGDHC, $\alpha$-ketoglutarate (or 2-OG) dehydrogenase complex; ADMA, $N^{G}, N^{G}$-dimethyl-L-arginine; L-NMA, $\mathrm{N}^{\mathrm{G}}$-methyl-L-arginine; 2-OG, 2-oxoglutarate.

exposed to hypoxia experience a transient increase in oxidative stress, it is not likely that ROS alone are involved. ${ }^{37,59}$ Indeed, it is more likely that the increase in oxidative stress in hypoxic cells is due to increased NO and RNS (including $\mathrm{ONOO}^{-}$) generated by mitochondrial $\mathrm{Cco} / \mathrm{NO} \cdot{ }^{37}$ It is now clear that Cco is sufficient for stabilization of HIF-1 $\alpha$, that cell and tissue NO levels increase in hypoxic cells and tissues, that $\mathrm{Cco} / \mathrm{NO}$ is at least partially responsible for this increase, and that this NO helps stabilize HIF-1 $\alpha .^{36,45,60,62}$ Ways in which this NO can stabilize HIF-1 $\alpha$ or affect the activity of HIF-1 are discussed in the following section.

\section{NO stabilizes HIF}

$\mathrm{NO}$ is capable of modifying hundreds of proteins within the cell, including those involved in HIF-1 $\alpha$ regulation (Figure 5). Although the majority of reports indicate that NO stabilizes HIF-1 $\alpha$, some reports suggest that it does not. These conflicting reports are most likely a result of different methodologies and cellular conditions. Although several early studies reported that NO destabilizes HIF-1 $\alpha$, these studies used exogenous NO donors. ${ }^{63,64}$ This is problematic 


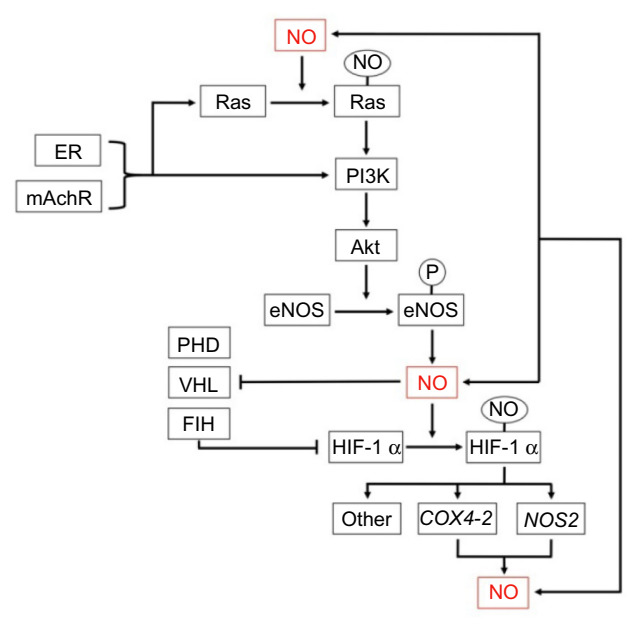

Figure $5 \mathrm{NO}$ is both upstream and downstream of PI3K/Akt and HIF-I signaling and can affect many proteins and pathways within the cell, including Ras and HIF-I $\alpha$. Notes: The specific modifications and functional effects $\mathrm{NO}$ exerts may be a result of differing sources and concentrations of $\mathrm{NO}$, or whether the added $\mathrm{NO}$ is the result of transnitrosylation via GADPH or NO release from GSNO.

Abbreviations: NO, nitric oxide; PI3K, phosphatidylinositide 3-Kinase; Akt, protein kinase B; HIF-I, hypoxia-inducible factor I; ER, estrogen receptors; $m A c h R$, muscarinic acetylcholine receptor; COX4-2, gene encoding cytochrome c oxidase subunit 4 isoform 2; NOS2, gene encoding inducible nitric oxide synthase; GAPDH, glyceraldehyde phosphate dehydrogenase; GSNO, S-nitrosylate glutathione.

because each NO donor has a different release profile, and it is unclear if the NO released from these donors was in the physiological range. Additionally, some donors, such as sodium nitroprusside, do not release NO, but rather facilitate transnitrosation, and should therefore be excluded from studies on nitrosylation. ${ }^{65}$ More recent papers have revealed a more complex picture. It now appears that short-term exposure to NO stabilizes HIF- $1 \alpha$ while chronic exposure to NO destabilizes HIF-1 $\alpha . .^{36,62,66-68}$ There is also evidence that NO can have different effects on HIF-1 $\alpha$ stability in hypoxia versus normoxia, with low levels of NO stabilizing HIF- $1 \alpha$ in hypoxia and high levels stabilizing it both in hypoxia and normoxia. ${ }^{36,69}$ It is important to emphasize that both NOS and heme-containing proteins such as Cco can produce $\mathrm{NO}$, and that both arginine and $\mathrm{O}_{2}^{-}$derived $\mathrm{NO}$ have been implicated in the stabilization of HIF- $1 \alpha .^{36,70}$

There are several possible ways in which NO can stabilize HIF-1. Cys533 and Cys800 of HIF-1 $\alpha$ are both susceptible to cysteine nitrosylation. Cys533-SNO allows HIF- $1 \alpha$ to escape normoxic degradation by preventing VHL from ubiquitinating HIF- $1 \alpha .{ }^{70}$ The consequences of nitrosylation at Cys 800 are not yet clear. Some experiments show increased transcriptional activity as a result of Cys800-SNO, while others show a decreased interaction with $\mathrm{p} 300$, which would result in decreased transcriptional activity. ${ }^{71,72} \mathrm{NO}$ can also inhibit PHD activity through nitrosylation of cysteine residues or by binding the catalytic iron. The ability of NO to bind the iron center of PHD appears to be affected by the concentration of 2-OG, because inhibition is only seen when 2-OG is unbound, indicating the metabolic status of the cell can alter the effects of NO on HIF- $1 \alpha$ stability. ${ }^{73} \mathrm{FIH}$ also appears to be inhibited by NO, and the mechanism is likely similar to that of PHD. ${ }^{74}$ Nitrosylation of Cys 162 in VHL prevents it from ubiquitinating hydroxylated HIF- $1 \alpha .{ }^{75}$ Finally, NO can both directly and indirectly inhibit $26 \mathrm{~S}$ proteasome activity, though indirect is likely the predominant mechanism, as direct inhibition only occurs at physiologically irrelevant NO concentrations. ${ }^{76}$ Although it has been reported that protein tyrosine nitration increases transiently upon cell exposure to hypoxia, to our knowledge, there is currently no data to suggest that HIF- $1 \alpha$ is tyrosine-nitrated, via $\mathrm{ONOO}^{-}$, under hypoxia. ${ }^{39}$

NO can also stabilize HIF- $1 \alpha$ via the PI3K/Akt signaling pathway. S-nitrosylation of Ras-Cys118 increases its activity, resulting in active PI3K/Akt signaling. ${ }^{77} \mathrm{PI} 3 \mathrm{~K} /$ Akt signaling then increases HIF- $1 \alpha$ expression and prevents its degradation through increased heat shock protein expression and also leads to phosphorylation and activation of eNOS. ${ }^{78-80}$ The increase in NO availability could then facilitate nitrosylation of HIF-1 $\alpha$, PHD2, or VHL, providing another means by which increased PI3K/Akt can increase HIF-1 $\alpha$ stability. PI3K can also interact with protein kinase $\mathrm{C} \zeta$ to decrease FIH mRNA levels and increase HIF-1 transcriptional activity. ${ }^{81}$

Finally, nitrosylation affects proteins that modify HIF- $1 \alpha$. HIF- $1 \alpha$ is acetylated at numerous sites by different acetyl transferases (Figure 2). The cofactor p300 complexes with HIF-1 and increases transcriptional activity though numerous mechanisms, including acetylation of Lys709 of HIF-1 $\alpha^{82}$ This acetyl transferase activity can be indirectly induced by NO through GAPDH-SNO, which then promotes $\mathrm{p} 300$ auto-acetylation and activity. ${ }^{83}$ Another way GAPDH-SNO influences HIF- $1 \alpha$ acetylation is by transnitrosylating and inhibiting Sirtuin 1 (SIRT1). ${ }^{84}$ Although SIRT1 deacetylates HIF- $1 \alpha$, the site and functional effects of this interaction are unclear, as conflicting reports have been published..$^{85,86}$ HIF- $1 \alpha$ is also phosphorylated at Ser641/3 by $\mathrm{p} 42 / 44$ MAPK, which increases HIF-1 nuclear localization and activity. ${ }^{87}$ NO signaling via cGMP causes a rapid induction of p42/44 MAPK, and NO-dependent inhibition of phosphatases allows prolonged MAPK signaling. ${ }^{88}$

As is easily seen in Figure 5, many upstream pathways induce NO production and increase intracellular NO levels, which can stabilize HIF-1 $\alpha$ and increase transcription of its target genes. Interestingly, two of these proteins, COX4-2 and iNOS, function in NO synthesis ${ }^{89}$ This places NO both 
upstream and downstream of HIF-1 signaling and intricately ties the two signaling pathways together.

\section{HIF-NO signaling in physiology}

Both HIF-1 and NO are essential for several cellular processes (Figure 6). Many physiological functions supported by NO will also have a role for HIF-1 and vice versa. These processes are discussed below.

\section{HIF-NO in development}

Knockout studies in mice have shown that HIF-1 is vital to development. ${ }^{90}$ Mice lacking HIF-1 die as embryos, with severe defects in the cardiovascular system and neural tube and large amounts of mesenchymal stem cell death. Stem cells in general are regulated by HIF-1 signaling and $\mathrm{O}_{2}$ levels. ${ }^{91}$ Oxygen gradients can guide stem cell migration, but embryonic stem cells and numerous adult stem cell populations actually grow more efficiently under hypoxic conditions, and a lack of HIF-1 negatively affects chondrogenesis, adipogenesis, and hematopoiesis due to a lack of vasculature and increased apoptosis. NO is also known to support stem cell functioning, partially due to its interaction with HIF-1. $\beta$-adrenergic receptor signaling promotes NO production and vasculogenesis in embryonic stem cells, and the use of $\beta$-blockers during pregnancy could potentially interfere with this important pathway. ${ }^{68,92}$

\section{$\mathrm{HIF-NO}$ in angiogenesis}

HIF-1 and NO continue to support angiogenesis past development. Following injury, the tissue surrounding the wound becomes quite hypoxic, which induces HIF-1 activity to promote revascularization of the wound and prevent cellular death. ${ }^{93} \mathrm{NO}$ is vital to healing wounds that sustain continued injury, likely by supporting HIF-1 stability and activity which then increases blood flow to the area. ${ }^{94}$ In

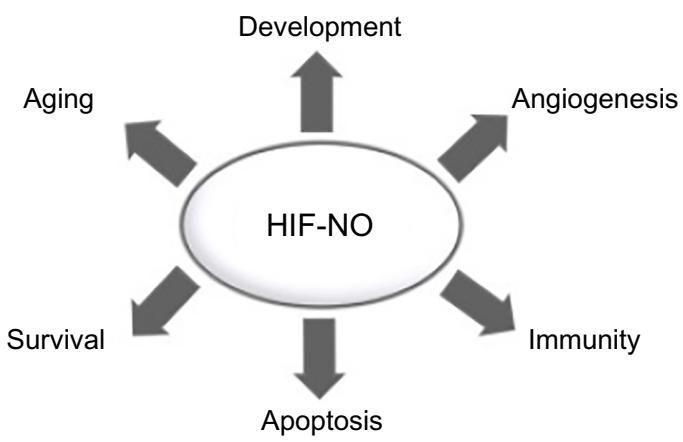

Figure 6 HIF-NO signaling supports several processes in the body, including development, angiogenesis, immunity, apoptosis, survival, and aging. Abbreviations: HIF, hypoxia-inducible factor; NO, nitric oxide. case of repeated injury, inflammatory cytokines, such as interleukin-1 $\beta$ (IL-1 $\beta$ ) or tumor-necrosis factor- $\alpha$ (TNF- $\alpha$ ), stimulate NO production through either PI3K/Akt/HIF-1 or $\mathrm{NF} \kappa \mathrm{B}$, which induces iNOS expression. This induction of HIF-1 then allows for revascularization of the wound, which expedites healing. ${ }^{95,96} \mathrm{NO}$ production is also stimulated by estradiol-17 $\beta$ (E2). E2 signals through the estrogen receptors (ER), resulting in PI3K/Akt-mediated phosphorylation of eNOS. ${ }^{97}$ While this activity is fundamental to uterine growth and angiogenesis following menstruation, E2-NOHIF signaling can also impact the vascular system in distal parts of the body. ${ }^{98,99}$ Finally, acetylcholine (Ach) signaling via $\mathrm{mAchR}$ in cardiomyocytes results in NO-dependent HIF-1 stabilization, again using PI3K/Akt-mediated eNOS phosphorylation. ${ }^{67,100}$ This HIF-1 activity maintains cardiac function in response to stress not only by inhibiting TGF- $\beta$ signal transduction but also by promoting angiogenesis to relieve pressure on the heart. ${ }^{101,102}$

\section{HIF-NO in the immune system}

HIF-1 has important noncanonical roles in physiology. One such example is trained immunity, where myeloid cells adapt to current infections in order to prevent secondary infections. During trained immunity in primary human monocytes, there is a marked increase in glycolysis as a result of HIF-1 activity, as induced by $\mathrm{P} 13 \mathrm{~K} / \mathrm{Akt} / \mathrm{mTOR}$. This increase in glycolysis and the resulting changes to the cell are a fundamental part of trained immunity, as rapamycin, an inhibitor of mTOR, prevents the shift toward glycolysis and training in monocytes. This training can be initiated by $\beta$-glucan signaling, which is known to increase NO production. ${ }^{103}$ Another way HIF-1 and NO can affect the immune system is by aiding the innate immune system in fighting infections by numerous bacteria, including Mycobacterium tuberculosis (Tb). ${ }^{104}$ Priming of white blood cells by NO prior to Tb infection stabilized HIF-1 $\alpha$, and leukocytes that had been exposed to NO were then more effective at killing bacteria and preventing infection, due to iNOS induction. ${ }^{105} \mathrm{NO}$ can then kill $\mathrm{Tb}$ cells by multiple mechanisms, including induction of apoptosis. ${ }^{106}$

\section{HIF-NO in apoptosis/cell survival}

HIF-1 can induce apoptosis or promote cellular survival. Which pathway HIF-1 affects is dependent on the cell type and microenvironment, and NO is a crucial determinant. In support of apoptosis, HIF-1 induces expression of BNIP3, a proapoptotic Bcl-2 family protein, while also stabilizing p53. ${ }^{107}$ Both of these actions can be induced by exposure to NO, likely due to its stabilization of HIF- $1 \alpha \cdot{ }^{108,109}$ Oppositely, 
NO can nitrosylate procaspase-3, which prevents cleavage and activation, and therefore apoptosis. ${ }^{110} \mathrm{NO}$ can also signal to nearby cells and induce HIF-1 and EPO production, which is neuroprotective. ${ }^{111}$ Concentration and duration of NO exposure seem to be decisive in determining whether NO has a pro- or antiapoptotic effect. ${ }^{112,113}$ However, $\mathrm{O}_{2}$ levels also likely play a role, as signaling from $\mathrm{ONOO}^{-}$can have a very different outcome than NO signaling, with much of the apoptotic effects previously attributed to NO actually being the result of increased $\mathrm{ONOO}^{-} .{ }^{114}$ Unfortunately, ROS levels were not measured in many publications looking at NO in apoptosis, so it is difficult to determine if it is in fact the differentiating factor.

\section{HIF-NO in autophagy/mitophagy}

While BNIP3 is known for its role in apoptosis, it can also induce autophagy. ${ }^{115}$ Autophagy is a way for cells to take in damaged structures and use the recycled materials for energy production. In hypoxia, autophagy of mitochondria, or mitophagy, serves as a source of nutrients and also decreases ROS production by eliminating damaged mitochondria that have increased electron leakage. ${ }^{116}$ In addition to promoting mitophagy, HIF-1 modulates expression of components of oxidative phosphorylation. HIF-1 increases the expression of COX4-2, while also increasing COX4-1 degradation through increased expression of the protease LON. COX4-2 increases electron transfer rates, which decreases the rate of ROS production while simultaneously increasing ATP production. ${ }^{37,89}$ As a paralog of yeast $C O X 5 b$, mammalian COX4-2 is also likely to increase NO synthesis by $\mathrm{Cco} /$ NO (see "Nitrite-dependent NO synthesis by mitochondrial cytochrome c oxidase" section).

\section{HIF-NO in aging}

There is evidence that HIF-1 lowers the expression of mitochondrially-encoded proteins by inhibiting Myc and decreasing the activity of mitochondrial transcription factor A (TFAM), a factor necessary for expression of mitochondrial genes. This process involves a decrease in SIRT1 activity leading to a decrease in VHL functioning, and is dependent on AMP-activated protein kinase (AMPK) switching away from a peroxisome proliferator-activated receptor $\gamma$ coactivator $1 \alpha / \beta$ (PGC-1 $\alpha / \beta$ )-dependent mechanism of mitochondria biogenesis. This occurs during hypoxia, but it also seems as though it can be induced by an increase in NADH:NAD ${ }^{+}$, resulting in a "pseudohypoxic" state. This psuedohypoxic state develops as cells age and is claimed to be causative of the decrease in mitochondrial function that is central to aging. ${ }^{117}$
However, the role of HIF-1 in aging is not so simple, and there is an abundance of contradictory information. As mentioned, there is evidence that SIRT1 both activates and inhibits HIF-1 by deacetylating HIF-1 $\alpha$ and affecting the ability of p300 to bind. ${ }^{85,86}$ In addition, HIF-1 decreases PGC-1 $\beta$ expression, though again as a result of decreased Myc activity, and TFAM levels were seen to be unchanged by fluctuations in HIF-1 or Myc activity. ${ }^{118}$ In Caenorhabditis elegans, both stabilization and deletion of HIF-1 increase lifespan, though each one by different methods. Constitutive HIF-1 stabilization decreased damage from oxidants and heat in a manner that did not rely on Forkhead box O (FOXO) or nuclear factor-like 2 (NRF2), which are both archetypal longevity proteins. Loss of HIF-1, however, increased lifespan in a FOXO and NRF2-dependent manner. ${ }^{119}$ Similarly, another group found that $C$. elegans HIF-1 knockouts had increased lifespan under nonrestricted diets, but when calorically restricted (CR), loss of HIF-1 decreased the lifespan extension typically conferred by CR, indicating HIF-1 may play an important role in the mitohormesis necessary for CR-dependent lifespan elongation. ${ }^{120}$

How does NO then relate to HIF-1 and aging? As mentioned, low levels of NO signal to the cell and induce an antioxidant response, while large amounts, especially during normoxia, causes a great deal of damage via $\mathrm{ONOO}^{-}$. However, NO is also known to induce mitochondrial biogenesis by nitrosylation and activation of PGC- $1 \alpha$, and is vital to lifespan elongation by CR. ${ }^{121}$ Increased NO alone can increase lifespan in C. elegans and yeast by activating cellular stress defenses and increasing mitochondrial biogenesis. ${ }^{50,122}$ Ultimately, whether HIF-1 and NO promote apoptosis versus survival or premature aging versus longevity seems to be dependent on the duration of HIF-1 stabilization, NO concentration, and the cellular microenvironment, specifically in regards to nutrient availability. ${ }^{123,124}$

\section{HIF-NO signaling in pathophysiology}

HIF-1 dysregulation underlies many different pathologies, including cancer, neurodegenerative disease, and ischemia/ reperfusion.

\section{HIF-NO and cancer}

Solid tumors have long been known to be quite hypoxic, and an important step in tumor growth and metastasis is tumor vascularization, a process facilitated by HIF-1. ${ }^{125}$ However, even normoxic tumors can have HIF-1-dependent VEGF expression, likely due to stabilization from NO. Colon adenomas expressing iNOS had higher levels of VEGF, and this then correlated with 
an increased chance of progression to carcinoma. ${ }^{126}$ In addition, breast cancer tissues show a higher level of iNOS and eNOS activity, especially in highly invasive tumors. ${ }^{127}$

The relationship between HIF, NO, and cancer is not so simple, in part due to the complexities explored previously (Figure 6). As mentioned, HIF-1 activity halts cell cycle progression by suppressing Myc and can also initiate apoptosis through BNIP3 expression and increased p53 activity, activities considered to be tumor-suppressive. ${ }^{128,129} \mathrm{NO}$ is also known to be antiproliferative, part of which is attributable to it sequestering E2F and decreasing Myc activity. ${ }^{130}$ Renal clear cell carcinoma is the cancer most frequently associated with HIF-1, as VHL deficiency is often central to renal clear cell carcinoma development. However, an examination of the contributions each HIF isoform makes in carcinogenesis revealed that HIF-1 slowed tumor growth while HIF-2 promoted it. ${ }^{131}$ In breast cancer, it was seen in multiple studies that HIF-1 stabilization in cancer-associated fibroblasts increased tumor growth while HIF-1 stabilization in breast cancer cells decreased growth. This has been attributed to HIF-1 halting the cell cycle and promoting autophagy. ${ }^{132,133}$

Of course, HIF-1 stabilization is not sufficient for cancer, and accompanying mutations may dictate whether HIF-1 and NO play a predominantly oncogenic or tumor-suppressive role. For example, if p53 is nonfunctional, as it is in many tumors, then it is irrelevant that HIF-1 and NO promote p53 accumulation and the balance may tip toward oncogenesis (Figure 7). ${ }^{134}$ Similarly, if Myc is mutated such that HIF-1 and NO no longer dampens its activity then the cumulative action of HIF-NO may be cancer promoting. As with aging, whether HIF-1 and NO promote tumor survival and metastasis or slow tumor growth comes down to microenvironment. While autophagy slows growth in cancer cells, it also allows survival until blood flow is restored when tumor cells are very hypoxic..$^{30}$ In addition, autophagy induced by hypoxia and nutrient deprivation during chemotherapy contributes to the resistance of certain cancers to treatment by decreasing cellular uptake of chemotherapeutic molecules. ${ }^{135,136}$ On the other hand, increased angiogenesis allows increased delivery of chemotherapeutic molecules, which would increase the efficacy of chemotherapy. ${ }^{137}$ Similarly, subcutaneous astrocytomas that do not express HIF-1 or VEGF necrotize due to prolonged hypoxia and nutrient deprivation, whereas intracranial astrocytomas lacking HIF-1 or VEGF migrate to higher $\mathrm{O}_{2}$ concentrations to survive. ${ }^{138}$ These differential effects of HIF-1 are likely a product of the large number of pathways HIF-1 can affect, and the circumstances under which HIF-1 is acting.

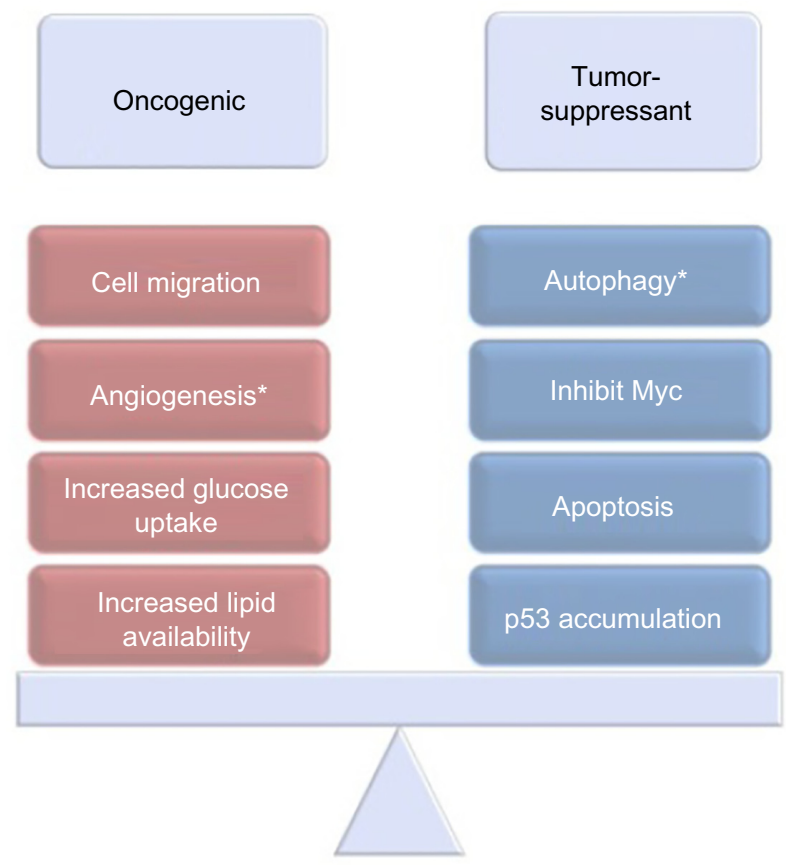

Figure 7 Oncogenic and tumor suppressive activities of HIF-I.

Notes: HIF-I has both oncogenic and tumor suppressive activities. While HIF-I does increase cell migration, angiogenesis, glucose uptake, and lipid availability, all of which promote tumor growth and metastasis, HIF-I also increases autophagy, apoptosis, and p53 accumulation and decreases Myc activity, all of which slow tumor growth and progression. Certain activities indicated with an * can be either oncogenic or tumor suppressive, depending on the specific tumor and its environment. Abbreviation: HIF-I, hypoxia-inducible factor I.

\section{HIF-NO and neurodegenerative disease}

Another subset of diseases that may be exacerbated by HIF-NO signaling is neurodegenerative diseases. In Alzheimer disease (AD), $\beta$-amyloid $(A \beta)$ can stimulate IL- $1 \beta$ and TNF $\alpha$ production, which in turn stimulate iNOS expression through NFKB and PI3K/Akt/HIF-1. ${ }^{95,96}$ This increased NO production, coupled with the increased $\mathrm{O}_{2}^{-}$seen in $\mathrm{AD}$, will form $\mathrm{ONOO}^{-}$which can then cause severe damage and potentially lead to apoptosis. ${ }^{139}$ There is also a tentative link between $\mathrm{AD}$ and intermittent hypoxia, which causes HIF- $1 \alpha$ accumulation, indicating HIF-1 could contribute to the genesis of AD. ${ }^{140}$ Hypoxia promotes $A \beta$ plaque formation, due to a HIF- $1 \alpha$-dependent increase in $\beta$-secretase expression, which together with $\gamma$-secretase cleaves $\beta$-amyloid precursor protein (APP) into $\mathrm{A} \beta .^{141}$

Alternatively, a lack of HIF-1 may contribute to pathogenesis by decreasing aerobic glycolysis, which has an important function in neuronal development and remodeling. ${ }^{142} \mathrm{NO}$ from distal cells enhances aerobic glycolysis in the brain by inducing HIF-1 $\alpha$ accumulation, which then increases expression of glycolytic enzymes. ${ }^{143}$ In AD, there is a decrease in aerobic glycolysis concomitant with 
an increase in $A \beta$ deposition in key areas of the brain most affected by $\mathrm{AD}$, including the default mode network. Aerobic glycolysis is neuroprotective, in part due to the increase in NADH that allows continual glutathione reduction and maintenance of cellular redox state and also due to the high lactate production. ${ }^{142}$ Lactate itself is quite important to normal brain function, as it can improve memory formation, provide a readily available source of energy, and also improve cerebral blood flow, likely through a positive feedback mechanism with HIF-1. ${ }^{144}$ In fact, HIF-1 expression alone seems to have neuroprotective properties, and prevents A $\beta$-induced cell death. ${ }^{145}$ On a larger scale, decreased cerebral blood flow, which is associated with increased severity of various dementias, including $\mathrm{AD}$, can be increased by dietary nitrate, which can be converted to $\mathrm{O}_{2}^{-}$and then $\mathrm{NO}$ by $\mathrm{O}_{2}^{-}$-dependent $\mathrm{NO}$ synthesis. ${ }^{146}$

\section{HIF-NO and ischemia-reperfusion}

HIF-NO signaling is important for minimizing oxidative damage and infarct size following an ischemic attack and subsequent reperfusion, especially in relation to pre-/ postconditioning. While there is minimal ROS production during prolonged ischemia, upon reperfusion there is a large burst of ROS production, which contributes to the massive cell death following an ischemic attack. ${ }^{147}$ Ischemic preconditioning involves cutting blood flow for several minutes and reperfusing prior to the prolonged ischemic event, while postconditioning involves several cycles of brief ischemia-reperfusion following prolonged ischemia. ${ }^{148} \mathrm{HIF}$ and NO have both been implicated in the mechanism underlying the protective effects of pre- and postconditioning. L-arginine supplementation during postconditioning resulted in significantly decreased infarct size and cognitive deficits following global cerebral ischemia in mice. ${ }^{149}$ In kidneys, the beneficial effects of preconditioning were found to be a result of Akt activation of eNOS, which then stabilized HIF-1, and all benefits of preconditioning were abolished when this pathway was inhibited at any level. ${ }^{150}$ HIF-1 can then decrease ROS production upon reperfusion by altering mitochondrial metabolism, increasing adenosine levels, and also by inducing small levels of ROS production that then elicit an antioxidant response. ${ }^{151}$ Cumulatively, this results in cells producing less ROS upon reperfusion and also being adequately prepared for an oxidative insult. ${ }^{152}$

\section{Targeting HIF-NO in therapies}

Because there are diseases associated with both increased and decreased HIF-NO signaling, there is a need for therapeutics that decrease and increase HIF-NO signaling, respectively.
While NO does affect HIF-1 activity, it has a plethora of other effects as well, so therapeutics that systemically increase NO levels have limited application. As mentioned, L-arginine supplementation during ischemic postconditioning reduces damage following cerebral ischemia, and may also help following cardiac ischemia. ${ }^{149} \mathrm{~L}$-arginine or nitrate/nitrite supplementation can also increase global blood flow, and may help diseases or disease-associated complication resulting from $\mathrm{O}_{2}$ or nutrient deprivation. This includes peripheral diabetic neuropathy, diabetic lesions, and vascular dementias and other neurodegenerative diseases exacerbated by inadequate blood flow. ${ }^{146,153,154}$ Near-infrared light can also stimulate Cco-NO activity, and this approach to increasing $\mathrm{NO}$ production would prevent systemic increases in NO production. ${ }^{49}$ This is especially relevant to diabetes, where NO production could help peripheral neuropathy and ulcer healing. However, it could promote diabetic retinopathy by increasing ocular angiogenesis. ${ }^{155}$ But again, increasing NO production is nonspecific and targeting pathways downstream of NO, such as HIF-1, is more viable and would minimize undesirable side effects.

HIF-1 activity can be therapeutically affected by altering the activity of PHD2, VHL, or any or HIF-1's other effectors. A recent study exploring the safety and efficacy of a PHD inhibitor in peripheral artery disease, which is defined by insufficient peripheral blood flow, found the therapy to be ineffective, although this may be due to the short duration of treatment. ${ }^{156}$ There is also interest in using PHD inhibitors during ischemia, which has shown to be quite effective in animal models but has not yet undergone clinical trials. ${ }^{157,158}$ However, it is important to note that drugs that affect PHDs still may not be specific to HIF-1, as PHD inhibition will also likely increase HIF-2 and HIF-3 stability. This is especially relevant to cancer therapeutics, where HIF-1 and HIF-2 can have profoundly different effects on tumor aggressiveness. ${ }^{131}$

Targeting the downstream oncogenic activities of HIF-1 or HIF-2 may be the most successful course of action in developing cancer therapeutics, as it will prevent blocking the tumor-suppressive activities associated with increased HIF-1 activity. While anti-VEGF signaling therapies have been explored and can be quite effective, especially in conjunction with fibroblast growth factor signaling inhibitors, many tumors can evade treatment by inducing other pathways that ultimately increase migration. ${ }^{159,160}$ This harkens back to the importance of microenvironment in determining the effect of a HIF-1 or VEGF knockout on tumor progression. ${ }^{138}$ A more complete understanding of the factors that dictate these differential responses will lead to more effective cancer therapies. 


\section{Conclusion}

In the past 20 years, HIF-1 has gone from being a key factor in hypoxia to a key factor involved in several normoxic and hypoxic pathways and pathologies. Because HIF-1 is involved in so many pathways and can directly and indirectly affect expression of over 1,000 genes, an understanding of its regulation is paramount to understanding its role in physiology and pathophysiology. ${ }^{24}$ Cellular NO levels and NO signaling are important components of HIF-1 stabilization and signaling, so understanding the intricacies of their formation and targeting within the cell is important. An outline for the crosstalk between NO and HIF signaling has just begun to emerge. Going forward, it will be important to examine: the contributions of both arginine and $\mathrm{O}_{2}^{-}$-dependent pathways for NO synthesis to HIF-1 function under hypoxic and normoxic conditions; the roles of cysteine nitrosylation and tyrosine nitration in HIF-NO signaling; and the relationship between NO posttranslational modifications and other posttranslational events that are involved in HIF-1 signaling. With an increased understanding of mechanisms underlying these processes, more accurate and effective therapies can be developed for the growing number of diseases influenced by HIF-NO signaling.

\section{Acknowledgments}

This work was sponsored by National Institutes of Health Grant 30228 and a gift from the Leslie F and Josephine Bailey Trust.

\section{Disclosure}

The authors report no conflicts of interest in this work.

\section{References}

1. Semenza G, Wang G. A nuclear factor induced by hypoxia via de novo protein synthesis binds to the human erythropoietin gene enhancer at a site required for transcriptional activation. Mol Cell Biol. 1992;12: 5447.

2. Wang G, Jiang B, Rue E, Semenza G. Hypoxia-inducible factor 1 is a basic-helix-loop-helix-PAS heterodimer regulated by cellular $\mathrm{O}_{2}$ tension. Proc Natl Acad Sci U S A. 1995;92:5510-5514.

3. Takahata S, Sogawa K, Kobayashi A, et al. Transcriptionally active heterodimer formation of an Arnt-like PAS protein, Arnt3, with HIF-1a, HLF, and clock. Biochem Biophys Res Commun. 1998;248: 789-794.

4. Sena J, Wang L, Heasley L, Hu C. Hypoxia regulates alternative splicing of HIF and non-HIF target genes. Mol Cancer Res. 2014;12(9): 1233-1243.

5. Makino Y, Kanopka A, Wilson W, Tanaka H, Poellinger L. Inhibitory PAS domain protein (IPAS) is a hypoxia-inducible splicing variant of the hypoxia-inducible factor-3 $\alpha$ locus. J Biol Chem. 2002;277(36): 32405-32408.

6. Maltepe E, Keith B, Arsham A, Brorson J, Simon M. The role of ARNT2 in tumor angiogenesis and the neural response to hypoxia. Biochem Biophys Res Commun. 2000;273:231-238.
7. Ruas J, Poellinger L, Pereira T. Functional Analysis of Hypoxiainducible Factor- $1 \alpha$-mediated transactivation: identification of amino acid residues critical for transcriptional activation and/or interaction with Creb-binding protein. J Biol Chem. 2002;277:38723-38730.

8. Kewley R, Whitelaw M, Chapman-Smith A. The mammalian basic helix-loop-helix/PAS family of transcriptional regulators. Int J Biochem Cell Biol. 2004;36:189-204.

9. Wiesener M, Jürgensen J, Rosenberger C, et al. Widespread hypoxiainducible expression of HIF-2 $\alpha$ in distinct cell populations of different organs. FASEB J. 2003;17:271-273.

10. Prabhakar N, Semenza G. Adaptive and maladaptive cardiorespiratory responses to continuous and intermittent hypoxia mediated by hypoxia-inducible factors 1 and 2. Physiol Rev. 2012;92: 967-1003.

11. Ikeda M, Nomura M. cDNA cloning and tissue-specific expression of a novel basic helix-loop-helix/PAS protein (BMAL1) and identification of alternatively spliced variants with alternative translation initiation site usage. Biochem Biophys Res Commun. 1997;233: 258-264.

12. Mole D, Blancher C, Copley R, et al. Genome-wide association of hypoxia-inducible factor (HIF)- $1 \alpha$ and HIF- $2 \alpha$ DNA binding with expression profiling of hypoxia-inducible transcripts. J Biol Chem. 2009;284(25):16767-16775.

13. Semenza G. HIF-1: upstream and downstream of cancer metabolism. Curr Opin Genet Dev. 2010;20:51-56.

14. Scortegagna M, Ding K, Zhang Q, et al. HIF- $2 \alpha$ regulates murine hematopoietic development in an erythropoietin-dependent manner. Blood. 2005;105:3133-3140.

15. Ratcliffe P. HIF-1 and HIF-2: working alone or together in hypoxia? J Clin Invest. 2007;117:862-865.

16. Makino Y, Cao R, Svensson K, et al. Inhibitory PAS domain protein is a negative regulator of hypoxia-inducible gene expression. Nature. 2001;414(6863):550-554

17. Jaakkola P, Mole D, Tian Y, et al. Targeting of HIF- $\alpha$ to the von HippelLindau ubiquitylation complex by $\mathrm{O} 2$-regulated prolyl hydroxylation. Science. 2001;292(5516):468-472.

18. Maxwell P, Wiesener M, Chang G, et al. The tumour suppressor protein VHL targets hypoxia-inducible factors for oxygen-dependent proteolysis. Nature. 1999;399(6733):271-275.

19. Berra E, Benizri E, Ginouvès A, Volmat V, Roux D, Pouysségur J. HIF prolyl-hydroxylase 2 is the key oxygen sensor setting low steady-state levels of HIF-1 $\alpha$ in normoxia. EMBO J. 2003;22:4082-4090.

20. Paltoglou S, Roberts B. HIF- $1 \alpha$ and EPAS ubiquitination mediated by the VHL tumour suppressor involves flexibility in the ubiquitination mechanism, similar to other RING E3 ligases. Oncogene. 2006;26:604-609.

21. Lando D, Peet D, Whelan D, Gorman J, Whitelaw M. Asparagine hydroxylation of the HIF transactivation domain: a hypoxic switch. Science. 2002;295(5556):858-861.

22. Zhang N, Fu Z, Linke S, et al. The asparaginyl hydroxylase factor inhibiting HIF-1 $\alpha$ is an essential regulator of metabolism. Cell Metab. 2010;11:364-378.

23. Masson N, Singleton R, Sekirnik R, et al. The FIH hydroxylase is a cellular peroxide sensor that modulates HIF transcriptional activity. EMBO Rep. 2012;13:251-257.

24. Semenza G. HIF-1 mediates metabolic responses to intratumoral hypoxia and oncogenic mutations. J Clin Invest. 2013;123:3664-3671.

25. Schödel J, Oikonomopoulos S, Ragoussis J, Pugh C, Ratcliffe P, Mole D. High-resolution genome-wide mapping of HIF-binding sites by ChIP-seq. Blood. 2011;117(23):207-217.

26. Carroll V, Ashcroft M. Role of hypoxia-inducible factor (HIF)- $1 \alpha$ versus HIF-2 $\alpha$ in the regulation of HIF target genes in response to hypoxia, insulin-like growth factor-I, or loss of von Hippel-Lindau function: implications for targeting the HIF pathway. Cancer Res. 2006;66:6264-6270.

27. Jung F, Palmer L, Zhou N, Johns R. Hypoxic regulation of inducible nitric oxide synthase via hypoxia inducible factor-1 in cardiac myocytes. Circ Res. 2000;86:319-325. 
28. Kim J, Tchernyshyov I, Semenza G, Dang C. HIF-1-mediated expression of pyruvate dehydrogenase kinase: a metabolic switch required for cellular adaptation to hypoxia. Cell Metab. 2006;3:177185.

29. Huang D, Li T, Li X, et al. HIF-1-mediated suppression of acylCoA dehydrogenases and fatty acid oxidation is critical for cancer progression. Cell Rep. 2014;25(8):1930-1942.

30. Zhang H, Bosch-Marce M, Shimoda L, et al. Mitochondrial autophagy is an HIF-1-dependent adaptive metabolic response to hypoxia. $J$ Biol Chem. 2008;283:10892-10903.

31. Jiang B, Agani F, Passaniti A, Semenza G. V-SRC induces expression of hypoxia-inducible factor 1 (HIF-1) and transcription of genes encoding vascular endothelial growth factor and enolase 1: involvement of HIF-1 in tumor progression. Cancer Res. 1997;57(23):5328-5335.

32. Eliceiri B, Paul R, Schwartzberg P, Hood J, Leng J, Cheresh D. Selective requirement for Src kinases during VEGF-induced angiogenesis and vascular permeability. Mol Cell. 1999;4:915-924.

33. Mukhopadhyay D, Tsiokas L, Zhou X, Foster D, Brugge J, Sukhatme V. Hypoxic induction of human vascular endothelial growth factor expression through c-Src activation. Nature. 1995;375(6532):577-581.

34. Gray M, Zhang J, Ellis L, et al. HIF-1 $\alpha$, STAT3, CBP/p300 and Ref-1/ APE are components of a transcriptional complex that regulates Srcdependent hypoxia-induced expression of VEGF in pancreatic and prostate carcinomas. Oncogene. 2005;24:3110-3120.

35. Moncada S, Palmer R, Higgs E. Nitric oxide: physiology, pathophysiology, and pharmacology. Pharmacol Rev. 1991;43:109-142.

36. Ball K, Nelson A, Foster D, Poyton R. Nitric oxide produced by cytochrome c oxidase helps stabilize HIF-1 $\alpha$ in hypoxic mammalian cells. Biochem Biophys Res Commun. 2012;420:727-732.

37. Poyton R, Ball K, Castello P. Mitochondrial generation of free radicals and hypoxic signaling. Trends Endocrinol Metab. 2009;20:332-340.

38. Benhar M, Stamler J. A central role for S-nitrosylation in apoptosis. Nat Cell Biol. 2005;7:645-646.

39. Castello P, David P, McClure T, Crook Z, Poyton R. Mitochondrial cytochrome oxidase produces nitric oxide under hypoxic conditions: implications for oxygen sensing and hypoxic signaling in eukaryotes. Cell Metab. 2006;3:277-287.

40. Fang F. Antimicrobial reactive oxygen and nitrogen species: concepts and controversies. Nat Rev Microbiol. 2004;2:820-832.

41. Liu L, Yan Y, Zeng M, et al. Essential roles of S-nitrosothiols in vascular homeostasis and endotoxic shock. Cell. 2004;116:617-628.

42. Hara M, Agrawal N, Kim S, et al. S-nitrosylated GAPDH initiates apoptotic cell death by nuclear translocation following Siahl binding. Nat Cell Biol. 2005;7:665-674.

43. Alderton W, Cooper C, Knowles R. Nitric oxide synthases: structure, function and inhibition. Biochem J. 2001;357:593.

44. Zweier J, Wang P, Samouilov A, Kuppusamy P. Enzyme-independent formation of nitric oxide in biological tissues. Nat Med. 1995;1: 804-809.

45. van Faassen E, Bahrami S, Feelisch M, et al. Nitrite as regulator of hypoxic signaling in mammalian physiology. Med Res Rev. 2009;29: 683-741.

46. Vitturi D, Patel R. Current perspectives and challenges in understanding the role of nitrite as an integral player in nitric oxide biology and therapy. Free Radical Biol Med. 2011;51:805-812.

47. Poyton R, Ball K. Therapeutic photobiomodulation: nitric oxide and a novel function of mitochondrial cytochrome C oxidase. Discov Med. 2011;11:154-159.

48. Hematian S, Siegler M, Karlin K. Heme/copper assembly mediated nitrite and nitric oxide interconversion. J Am Chem Soc. 2012;134: 18912-18915.

49. Ball K, Castello P, Poyton R. Low intensity light stimulates nitritedependent nitric oxide synthesis but not oxygen consumption by cytochrome c oxidase: implications for phototherapy. $J$ Photochem Photobiol B. 2011;102:182-191.

50. Li B, Skinner C, Castello P, et al. Identification of potential calorie restriction-mimicking yeast mutants with increased mitochondrial respiratory chain and nitric oxide levels. J Aging Res. 2011;2011:1-16.
51. Poyton R, Castello P, Ball K, Woo D, Pan N. Mitochondrial nitritedependent NO production and hypoxic signaling. Ann N Y Acad Sci. 2009;1177:48-56.

52. Alzawahra W, Talukder M, Liu X, Samouilov A, Zweier J. Heme proteins mediate the conversion of nitrite to nitric oxide in the vascular wall. Am J Physiol Heart Circ Physiol. 2008;295:H499-H508.

53. Tsikas D, Böger R, Sandmann J, Bode-Böger S, Frölich J. Endogenous nitric oxide synthase inhibitors are responsible for the L-arginine paradox. FEBS Lett. 2000;478:1-3.

54. Castello P, Woo D, Ball K, Wojcik J, Liu L, Poyton R. Oxygen-regulated isoforms of cytochrome $\mathrm{c}$ oxidase have differential effects on its nitric oxide production and on hypoxic signaling. Proc Natl Acad Sci U SA. 2008; $105: 8203-8208$.

55. Burke P, Poyton R. Structure/function of oxygen-regulated isoforms in cytochrome c oxidase. J Exp Biol. 1998;201:1163-1175.

56. Ray P, Huang B, Tsuji Y. Reactive oxygen species (ROS) homeostasis and redox regulation in cellular signaling. Cell Signal. 2012;24: 981-990.

57. Schieber M, Chandel N. ROS function in redox signaling and oxidative stress. Curr Biol. 2014;24:R453-R462.

58. Finkel T. Signal transductants by mitochondrial oxidants. J Biol Chem. 2012;297:4434-4440

59. Chua Y, Dufour E, Dassa E, et al. Stabilization of hypoxia-inducible factor-1 protein in hypoxia occurs independently of mitochondrial reactive oxygen species production. J Biol Chem. 2010;285:31277-31284.

60. Hoffman D, Brookes P. Oxygen sensitivity of mitochondrial reactive oxygen species generation depends on metabolic Conditions. J Biol Chem. 2009;284:16236-16245.

61. Chowdhury R, Godoy L, Thiantanawat A, Trudel L, Deen W, Wogan G. Nitric oxide produced endogenously is responsible for hypoxia-induced HIF-1 $\alpha$ stabilization in colon carcinoma cells. Chem Res Toxicol. 2012;25:2194-2202.

62. Huang L, Willmore W, Gu J, Goldberg M, Bunn H. Inhibition of hypoxia-inducible factor 1 activation by carbon monoxide and nitric oxide: implications for oxygen sensing and signaling. $J$ Biol Chem. 1999;274:9038-9044.

63. SogawaK, Numayama-TsurutaK,EmaM,AbeM,AbeH,Fujii-KuriyamaY. Inhibition of hypoxia-inducible factor 1 activity by nitric oxide donors in hypoxia. Proc Natl Acad Sci U SA. 1998;95:7368-7373.

64. Sandau K. Accumulation of HIF-1 $\alpha$ under the influence of nitric oxide. Blood. 2001;97:1009-1015.

65. Caneba C, Yang L, Baddour J, et al. Nitric oxide is a positive regulator of the Warburg effect in ovarian cancer cells. Cell Death Dis. 2014;5: e1302.

66. Kuwabara M, Kakinuma Y, Ando M, et al. Nitric oxide stimulates vascular endothelial growth factor production in cardiomyocytes involved in angiogenesis. Jpn J Physiol. 2006;56:95-101.

67. Sharifpanah F, Saliu F, Bekhite M, Wartenberg M, Sauer H. $\beta$-adrenergic receptor antagonists inhibit vasculogenesis of embryonic stem cells by downregulation of nitric oxide generation and interference with VEGF signaling. Cell Tissue Res. 2014;358:443-452.

68. Berchner-Pfannschmidt U, Tug S, Kirsch M, Fandrey J. Oxygen-sensing under the influence of nitric oxide. Cell Signal. 2010;22:349-356.

69. Li F, Sonveaux P, Rabbani Z, et al. Regulation of HIF-1 $\alpha$ stability through S-nitrosylation. Mol Cell. 2007;26:63-74.

70. Yasinska I, Sumbayev V. S-nitrosation of Cys-800 of HIF-1 $\alpha$ protein activates its interaction with $\mathrm{p} 300$ and stimulates its transcriptional activity. FEBS Lett. 2003;549:105-109.

71. Cho H, Ahn D, Park H, Yang E. Modulation of p300 binding by posttranslational modifications of the $\mathrm{C}$-terminal activation domain of hypoxia-inducible factor-1 $\alpha$. FEBS Lett. 2007;581:1542-1548.

72. Chowdhury R, Flashman E, Mecinović J, et al. Studies on the reaction of nitric oxide with the hypoxia-inducible factor prolyl hydroxylase domain 2 (EGLN1). J Mol Biol. 2011;410:268-279.

73. Park Y, Ahn D, Oh M, et al. Nitric oxide donor, ( \pm )-S-nitroso-Nacetylpenicillamine, stabilizes transactive hypoxia-inducible factor- 1 by inhibiting von Hippel-Lindau recruitment and asparagine hydroxylation. Mol Pharmacol. 2008;74:236-245. 
74. Palmer L, Doctor A, Chhabra P, et al. S-nitrosothiols signal hypoxiamimetic vascular pathology. J Clin Invest. 2007;117:2592-2601.

75. Liu H, Yu S, Zhang H, Xu J. Identification of nitric oxide as an endogenous inhibitor of $26 \mathrm{~S}$ proteasomes in vascular endothelial cells. PLoS One. 2014;9:e98486.

76. Castellano E, Downward J. RAS interaction with PI3K: more than just another effector pathway. Genes Cancer. 2011;2:261-274.

77. Hudson C, Liu M, Chiang G, et al. Regulation of hypoxia-inducible factor $1 \alpha$ expression and function by the mammalian target of rapamycin. Mol Cell Biol. 2002;22:7004-7014.

78. Zhou J. PI3K/Akt is required for heat shock proteins to protect hypoxiainducible factor 1 from pVHL-independent degradation. J Biol Chem. 2004;279:13506-13513.

79. Zeiher A, Dimmeler S, Fleming I, Fisslthaler B, Hermann C, Busse R. Activation of nitric oxide synthase in endothelial cells by Akt-dependent phosphorylation. Nature. 1999;399:601-605.

80. Datta K, Li J, Bhattacharya R, Gasparian L, Wang E, Mukhopadhyay D. Protein kinase $\mathrm{c}$ transactivates hypoxia-inducible factor by promoting its association with p300 in renal cancer. Cancer Res. 2004;64:456-462.

81. Geng H, Liu Q, Xue C, et al. HIF1 protein stability is increased by acetylation at lysine 709. J Biol Chem. 2012;287:35496-35505.

82. Arif M, Vedamurthy B, Choudhari R, et al. Nitric oxide-mediated histone hyperacetylation in oral cancer: target for a water-soluble HAT inhibitor, CTK7A. Chem Biol. 2010;17:903-913.

83. Kornberg M, Sen N, Hara M, et al. GAPDH mediates nitrosylation of nuclear proteins. Nat Cell Biol. 2010;12:1094-1100.

84. Lim J, Lee Y, Chun Y, Chen J, Kim J, Park J. Sirtuin 1 modulates cellular responses to hypoxia by deacetylating hypoxia-inducible factor $1 \alpha . \mathrm{Mol}$ Cell. 2010;38:864-878.

85. Laemmle A, Lechleiter A, Roh V, et al. Inhibition of SIRT1 impairs the accumulation and transcriptional activity of HIF- $1 \alpha$ protein under hypoxic conditions. PLoS One. 2012;7:e33433.

86. Mylonis I, Chachami G, Samiotaki M, et al. Identification of MAPK phosphorylation sites and their role in the localization and activity of hypoxia-inducible factor-1. J Biol Chem. 2006;281:33095-33106.

87. Callsen D, Pfeilschifter J, Brüne B. Rapid and delayed p42/p44 mitogenactivated protein kinase activation by nitric oxide: the role of cyclic GMP and tyrosine phosphatase inhibition. J Immunol. 1998;161: 4852-4858.

88. Fukuda R, Zhang H, Kim J, Shimoda L, Dang C, Semenza G. HIF-1 regulates cytochrome oxidase subunits to optimize efficiency of respiration in hypoxic cells. Cell. 2007;129:111-122.

89. Iyer N, Kotch L, Agani F, et al. Cellular and developmental control of $\mathrm{O} 2$ homeostasis by hypoxia-inducible factor 1alpha. Genes Dev. 1998; 12:149-162.

90. Simon M, Keith B. The role of oxygen availability in embryonic development and stem cell function. Nat Rev Mol Cell Biol. 2008;9: 285-296.

91. Mustafa R, Ahmed S, Gupta A, Venuto R. A comprehensive review of hypertension in pregnancy. J Pregnancy. 2012;2012:1-19.

92. Cowburn A, Alexander L, Southwood M, Nizet V, Chilvers E, Johnson R. Epidermal deletion of HIF-2a stimulates wound closure. J Invest Dermatol. 2014;134:801-808.

93. Luo J, Chen A. Nitric oxide: a newly discovered function on wound healing. Acta Pharmacol Sin. 2005;26:259-264.

94. Yang L, Guo X, Du C, et al. Interleukin-1 beta increases activity of human endothelial progenitor cells: involvement of PI3K-Akt signaling pathway. Inflammation. 2012;35:1242-1250.

95. Akama K, Van Eldik L. $\beta$-amyloid stimulation of inducible nitric-oxide synthase in astrocytes is interleukin-1beta - and tumor necrosis factoralpha (TNF $\alpha$ )-dependent, and involves a TNF $\alpha$ receptor-associated factor- and NFK B-inducing kinase-dependent signaling mechanism. J Biol Chem. 2000;275:7918-7924.

96. Johnson M, Grazul-Bilska A, Redmer D, Reynolds L. Effects of estradiol-17 $\beta$ on expression of mRNA for seven angiogenic factors and their receptors in the endometrium of ovariectomized (OVX) ewes. Endocrinology. 2006;30:333-342.
97. Reynolds L, Grazul-Bilska A, Redmer D. Angiogenesis in the female reproductive organs: pathological implications. Int J Exp Pathol. 2002;83:151-164.

98. Stirone C. Estrogen receptor activation of phosphoinositide-3 kinase, Akt, and nitric oxide signaling in cerebral blood vessels: rapid and long-term effects. Mol Pharmacol. 2005;67:105-113.

99. Hirota K, Fukuda R, Takabuchi S, et al. Induction of hypoxia-inducible factor 1 activity by muscarinic acetylcholine receptor signaling. J Biol Chem. 2004;279:41521-41528.

100. Wei H, Bedja D, Koitabashi N, et al. Endothelial expression of hypoxiainducible factor 1 protects the murine heart and aorta from pressure overload by suppression of TGF-signaling. Proc Natl Acad Sci U SA. 2012;109:E841-E850.

101. Sano M, Minamino T, Toko H, et al. p53-induced inhibition of Hif-1 causes cardiac dysfunction during pressure overload. Nature. 2007;446:444-448.

102. Cheng S, Quintin J, Cramer R, et al. mTOR-and HIF-1 $\alpha$-mediated aerobic glycolysis as metabolic basis for trained immunity. Science. 2014;345:1250684

103. Peyssonnaux C, Datta V, Cramer T, et al. HIF-1 $\alpha$ expression regulates the bactericidal capacity of phagocytes. J Clin Invest. 2005;115: 1806-1815

104. Elks P, Brizee S, van der Vaart M, et al. Hypoxia inducible factor signaling modulates susceptibility to mycobacterial infection via a nitric oxide dependent mechanism. PLoS Pathog. 2013;9: e1003789.

105. Herbst S, Schaible U, Schneider B. Interferon gamma activated macrophages kill mycobacteria by nitric oxide induced apoptosis. PLoS One. 2011;6:e19105.

106. Guo K, Searfoss G, Krolikowski D, et al. Hypoxia induces the expression of the pro-apoptotic gene BNIP3. Cell Death Differ. 2001;8: 367-376.

107. Zamora R, Vodovotz Y, Betten B, et al. Intestinal and hepatic expression of BNIP3 in necrotizing enterocolitis: regulation by nitric oxide and peroxynitrite. Am J Physiol Gastrointest Liver Physiol. 2005;289: G822-G830

108. Jawahir M, Nicholas S, Coughlan K, Sumbayev V. Apoptosis signalregulating kinase 1 (ASK1) and HIF-1 $\alpha$ protein are essential factors for nitric oxide-dependent accumulation of p53 in THP-1 human myeloid macrophages. Apoptosis. 2008;13:1410-1416.

109. Hess D, Matsumoto A, Kim S, Marshall H, Stamler J. Protein S-nitrosylation: purview and parameters. Nat Rev Mol Cell Biol. 2005;6:150-166.

110. Keswani S, Bosch-Marce M, Reed N, Fischer A, Semenza G, Hoke A Nitric oxide prevents axonal degeneration by inducing HIF-1dependent expression of erythropoietin. Proc Natl Acad Sci U S A. 2011;108:4986-4990.

111. Hortelano S, Traves P, Zeini M, Alvarez A, Bosca L. Sustained nitric oxide delivery delays nitric oxide-dependent apoptosis in macrophages contribution to the physiological function of activated macrophages. J Immunol. 2003;171:6059-6064.

112. Brüne B. Nitric oxide: NO apoptosis or turning it ON? Cell Death Differ. 2003;10:864-869.

113. Pacher P, Beckman J, Liaudet L. Nitric oxide and peroxynitrite in health and disease. Physiol Rev. 2007;87:315-424.

114. Bellot G, Garcia-Medina R, Gounon P, et al. Hypoxia-induced autophagy is mediated through hypoxia-inducible factor induction of BNIP3 and BNIP3L via their BH3 domains. Mol Cell Biol. 2009;29: 2570-2581

115. Solaini G, Baracca A, Lenaz G, Sgarbi G. Hypoxia and mitochondrial oxidative metabolism. Biochim Biophys Acta. 2010;1797:1171-1177.

116. Gomes A, Price N, Ling A, et al. Declining NAD+ induces a pseudohypoxic state disrupting nuclear-mitochondrial communication during aging. Cell. 2013;155:1624-1638.

117. Zhang H, Gao P, Fukuda R, et al. HIF-1 inhibits mitochondrial biogenesis and cellular respiration in VHL-deficient renal cell carcinoma by repression of C-MYC activity. Cancer Cell. 2007;11:407-420. 
118. Zhang Y, Shao Z, Zhai Z, Shen C, Powell-Coffman J. The HIF-1 hypoxia-inducible factor modulates lifespan in C. elegans. PLoS One. 2009;4:e6348.

119. Chen D, Thomas E, Kapahi P. HIF-1 modulates dietary restrictionmediated lifespan extension via IRE-1 in Caenorhabditis elegans. PLoS Genet. 2009;5:e1000486.

120. Nisoli E, Tonello C, Cardile A, et al. Calorie restriction promotes mitochondrial biogenesis by inducing the expression of eNOS. Science. 2005;310:314-317.

121. Gusarov I, Smolentseva O, Gautier L, Nudler E. Nitric oxide produced by bacteria extends Caenorhabditis elegans lifespan. Nitric Oxide. 2012;27:S46-S50.

122. Bagnall J, Leedale J, Taylor S, et al. Tight control of hypoxia-inducible factor-transient dynamics is essential for cell survival in hypoxia. J Biol Chem. 2014;289:5549-5564.

123. Poulsen R, Knowles H, Carr A, Hulley P. Cell differentiation versus cell death: extracellular glucose is a key determinant of cell fate following oxidative stress exposure. Cell Death Dis. 2014;5:e1074.

124. Bergers G, Benjamin L. Angiogenesis: tumorigenesis and the angiogenic switch. Nat Rev Cancer. 2003;3:401-410.

125. Ambs S, Merriam W, Bennett W, et al. Frequent nitric oxide synthase-2 expression in human colon adenomas: implication for tumor angiogenesis and colon cancer progression. Cancer Res. 1998;58:334-341.

126. Loibl S, von Minckwitz G, Weber S, et al. Expression of endothelial and inducible nitric oxide synthase in benign and malignant lesions of the breast and measurement of nitric oxide using electron paramagnetic resonance spectroscopy. Cancer. 2002;95:1191-1198.

127. Koshiji M, Kageyama Y, Pete E, Horikawa I, Barrett J, Huang L. HIF-1 $\alpha$ induces cell cycle arrest by functionally counteracting Myc. EMBO J. 2004;23:1949-1956.

128. Krick S, Eul B, Hänze J, et al. Role of hypoxia-inducible factor- $1 \alpha$ in hypoxia-induced apoptosis of primary alveolar epithelial type II cells. Am J Respir Cell Mol Biol. 2005;32:395-403.

129. Ciani E, Severi S, Contestabile A, Bartesaghi R, Contestabile A. Nitric oxide negatively regulates proliferation and promotes neuronal differentiation through N-Myc downregulation. J Cell Sci. 2004;117: $4727-4737$.

130. Raval R, Lau K, Tran M, et al. Contrasting properties of hypoxiainducible factor 1 (HIF-1) and HIF-2 in von Hippel-Lindau-associated renal cell carcinoma. Mol Cell Biol. 2005;25:5675-5686.

131. Chiavarina B, Whitaker-Menezes D, Migneco G, et al. HIF1-alpha functions as a tumor promoter in cancer-associated fibroblasts, and as a tumor suppressor in breast cancer cells. Cell Cycle. 2010;9: 3534-3551.

132. Capparelli C, Whitaker-Menezes D, Guido C, et al. CTGF drives autophagy, glycolysis and senescence in cancer-associated fibroblasts via HIF1 activation, metabolically promoting tumor growth. Cell Cycle. 2012;11:2272-2284.

133. Soussi T, Wiman K. Shaping genetic alterations in human cancer: the p53 mutation paradigm. Cancer Cell. 2007;12:303-312.

134. Amaravadi R. Autophagy-induced tumor dormancy in ovarian cancer. $J$ Clin Invest. 2008;118(12):3837-3840.

135. Zhou Y, Sun K, Ma Y, et al. Autophagy inhibits chemotherapy-induced apoptosis through downregulating Bad and Bim in hepatocellular carcinoma cells. Sci Rep. 2014;4:5382.

136. Bai X, Zhi X, Zhang Q, et al. Inhibition of protein phosphatase 2A sensitizes pancreatic cancer to chemotherapy by increasing drug perfusion via HIF-1 $\alpha$-VEGF mediated angiogenesis. Cancer Lett. 2014;355:281-287.

137. Blouw B, Song H, Tihan T, et al. The hypoxic response of tumors is dependent on their microenvironment. Cancer Cell. 2003;4: 133-146.

138. Esposito L, Raber J, Kekonius L, et al. Reduction in mitochondrial superoxide dismutase modulates alzheimer's disease-like pathology and accelerates the onset of behavioral changes in human amyloid precursor protein transgenic mice. J Neurosci. 2006;26:5167-5179.

139. Pan W, Kastin A. Can sleep apnea cause Alzheimer's disease? Neurosci Biobehav Rev. 2014;47:656-669.
140. Zhang X, Zhou K, Wang R, et al. Hypoxia-inducible Factor 1(HIF-1)mediated hypoxia increases BACE1 expression and beta-amyloid generation. J Biol Chem. 2007;282:10873-10880.

141. Vlassenko A, Raichle M. Brain aerobic glycolysis functions and Alzheimer's disease. Clin Transl Imaging. 2015;3:27-37.

142. Brix B, Mesters J, Pellerin L, Johren O. Endothelial cell-derived nitric oxide enhances aerobic glycolysis in astrocytes via HIF-1-mediated target gene activation. J Neurosci. 2012;32:9727-9735.

143. Newington J, Harris R, Cumming R. Reevaluating metabolism in Alzheimer's disease from the perspective of the astrocyte-neuron lactate shuttle model. J Neurodegener Dis. 2013;2013:1-13.

144. Soucek T, Cumming R, Dargusch R, Maher P, Schubert D. The regulation of glucose metabolism by HIF-1 mediates a neuroprotective response to amyloid beta peptide. Neuron. 2003;39:43-56.

145. Miller G, Tennille P, Morgan A, et al. Acute effect of a high nitrate diet on brain perfusion in older adults. Nitric Oxide. 2011;24:S28.

146. Näpänkangas J, Liimatta E, Joensuu P, Bergmann U, Ylitalo K, Hassinen I. Superoxide production during ischemia-reperfusion in the perfused rat heart: a comparison of two methods of measurement. J Mol Cell Cardiol. 2012;53:906-915.

147. Halkos M, Kerendi F, Corvera J, et al. Myocardial protection with postconditioning is not enhanced by ischemic preconditioning. Ann Thorac Surg. 2004;78:961-969.

148. Gulati P, Singh N. Evolving possible link between PI3K and NO pathways in neuroprotective mechanism of ischemic postconditioning in mice. Mol Cell Biochem. 2014;397:255-265.

149. Mahfoudh-Boussaid A, Zaouali M, Hadj-Ayed K, et al. Ischemic preconditioning reduces endoplasmic reticulum stress and upregulates hypoxia inducible factor- $1 \alpha$ in ischemic kidney: the role of nitric oxide. J Biomed Sci. 2012;19:7.

150. Cai Z, Zhong H, Bosch-Marce M, et al. Complete loss of ischaemic preconditioning-induced cardioprotection in mice with partial deficiency of HIF-1. Cardiovasc Res. 2007;77:463-470.

151. Semenza G. Hypoxia-inducible factor 1: regulator of mitochondrial metabolism and mediator of ischemic preconditioning. Biochin Biophys Acta. 2011;1813:1263-1268.

152. Witte M, Thornton F, Tantry U, Barbul A. L-arginine supplementation enhances diabetic wound healing: Involvement of the nitric oxide synthase and arginase pathways. Metabolism. 2002;51:1269-1273.

153. Bin-Jaliah I, El-Attar S, Khaleel E, El-Sayed L, Haidara M. Remedial effects of vitamin $\mathrm{E}$ and L-arginine on peripheral neuropathy in streptozotocin-induced diabetic rats. Am J Pharmacol Toxicol. 2014;9: 13-23.

154. Simo R, Sundstrom J, Antonetti D. Ocular anti-VEGF therapy for diabetic retinopathy: the role of VEGF in the pathogenesis of diabetic retinopathy. Diabetes Care. 2014;37:893-899.

155. Olson E, Demopoulos L, Haws T, et al. Short-term treatment with a novel HIF-prolyl hydroxylase inhibitor (GSK1278863) failed to improve measures of performance in subjects with claudication-limited peripheral artery disease. Vasc Med. 2014;19:473-482.

156. Reischl S, Li L, Walkinshaw G, Flippin L, Marti H, Kunze R. Inhibition of HIF prolyl-4-hydroxylases by FG-4497 reduces brain tissue injury and edema formation during ischemic Stroke. PLoS One. 2014;9: e84767.

157. Karuppagounder S, Ratan R. Hypoxia-inducible factor prolyl hydroxylase inhibition: robust new target or another big bust for stroke therapeutics? J Cereb Blood Flow Metab. 2012;32:1347-1361.

158. Casanovas O, Hicklin D, Bergers G, Hanahan D. Drug resistance by evasion of antiangiogenic targeting of VEGF signaling in late-stage pancreatic islet tumors. Cancer Cell. 2005;8:299-309.

159. Keunen O, Johansson M, Oudin A, et al. Anti-VEGF treatment reduces blood supply and increases tumor cell invasion in glioblastoma. Proc Natl Acad Sci U S A. 2011;108:3749-3754.

160. Benita Y, Kikuchi H, Smith A, Zhang M, Chung D, Xavier R. An integrative genomics approach identifies Hypoxia Inducible Factor-1 (HIF-1)-target genes that form the core response to hypoxia. Nucleic Acids Res. 2009;37:4587-4602. 
161. Gerber H, Condorelli F, Park J, Ferrara N. Differential transcriptional regulation of the two vascular endothelial growth factor receptor genes: Flt-1, but not Flk-1/KDR, is up-regulated by hypoxia. J Biol Chem. 1997;272:23659-23667.

162. Semenza G. Targeting HIF-1 for cancer therapy. Nat Rev Cancer. 2003;3:721-732.

163. Bergeron M, Yu A, Solway K, Semenza G, Sharp F. Induction of hypoxia-inducible factor-1 (HIF-1) and its target genes following focal ischaemia in rat brain. European J Neurosci. 1999;11:4159-4170.

164. Yang Z, Zou A. Transcriptional regulation of heme oxygenases by HIF- $1 \alpha$ in renal medullary interstitial cells. Am J Physiol Renal Physiol. 2001;281:F900-F908.

165. Jeong J, Bae M, Ahn M, et al. Regulation and destabilization of HIF-1 $\alpha$ by ARD1-mediated acetylation. Cell. 2002;111:709-720.
166. Pan Y, Mansfield K, Bertozzi C, et al. Multiple factors affecting cellular redox status and energy metabolism modulate hypoxia-inducible factor prolyl hydroxylase activity in vivo and in vitro. Mol Cell Biol. 2007;27(3):912-925.

167. Caito S, Rajendrasozhan S, Cook S, et al. SIRT1 is a redox-sensitive deacetylase that is post-translationally modified by oxidants and carbonyl stress. FASEB J. 2010;24(9):3145-3159.

168. Tyther R, McDonagh B, Sheehan D. Proteomics in investigation of protein nitration in kidney disease: Technical challenges and perspective from the sponaneously hypertensive rat. Mass Spectrom Rev. 2011;30(1):121-141.

169. Shi $\mathrm{Q}, \mathrm{Xu} \mathrm{H}, \mathrm{Yu} \mathrm{H}$, et al. Inactivation and reactivation of the mitochondrial -ketoglutarate dehydrogenase complex. J Biol Chem. 2011;286(20):17640-17648.

\section{Publish your work in this journal}

Research and Reports in Biochemistry is an international, peer-reviewed, open access journal publishing original research, reports, reviews and commentaries on all areas of biochemistry. The manuscript management system is completely online and includes a very quick and fair

\section{Dovepress}

peer-review system. Visit http://www.dovepress.com/testimonials.php to read real quotes from published authors. 